Article

\title{
Fabrication and Optimization of the Thermo-Sensitive Hydrogel Carboxymethyl Cellulose/Poly(N-isopropylacrylamide-co-acrylic acid) for U(VI) Removal from Aqueous Solution
}

\author{
Juan Tan ${ }^{1}$, Shuibo Xie ${ }^{2, *}$, Guohua Wang ${ }^{1}$, Chuck Wah Yu ${ }^{1}$, Taotao Zeng ${ }^{1}$, Pingli Cai ${ }^{3}$ \\ and Huayong Huang ${ }^{3}$ \\ 1 College of Civil Engineering, University of South China, Hengyang 421001, China; \\ Tanjuan0907@163.com (J.T.); wghcsu@163.com (G.W.); chuck.yu@upc.edu.cn (C.W.Y.); \\ biowater@126.com (T.Z.) \\ 2 Key Discipline Laboratory for National Defence of Biotechnology in Uranium Mining and Hydrometallurgy, \\ University of South China, Hengyang 421001, China \\ 3 Hunan Provincial Key Laboratory of Pollution Control and Resources Technology, University of South \\ China, Hengyang 421001, China; 430000725392@usc.edu.cn (P.C.); hhy@usc.edu.cn (H.H.) \\ * Correspondence: xiesbmr@263.net; Tel.: +86-139-7342-9689
}

Received: 18 October 2019; Accepted: 2 January 2020; Published: 7 January 2020

\begin{abstract}
In this work, the thermo-sensitive materials N-isopropylacrylamide (NIPAM) and acrylic acid (AA) were crosslinked with carboxymethyl cellulose (CMC) (CMC/P (NIPAM-co-AA)) via a free radical polymerization method for the removal of $\mathrm{U}(\mathrm{VI})$ from aqueous solution. The L16 $\left(4^{5}\right)$ orthogonal experiments were designed for the optimization of the synthesis condition. The chemical structures of the crosslinking hydrogel were confirmed by FTIR spectroscopy. The microstructural analyses were conducted though scanning electron microscopy (SEM) to show the pore structure of the hydrogel. The adsorption performance of the CMC/P (NIPAM-co-AA) hydrogel for the uptake of $\mathrm{U}(\mathrm{VI})$ from simulated wastewater was also investigated. The adsorption reached equilibrium within $1 \mathrm{~h}$. Under the reaction of $\mathrm{pH}=6$ and a temperature of $298 \mathrm{~K}$, an initial concentration of $\mathrm{U}(\mathrm{VI})$ of $5 \mathrm{mg} \cdot \mathrm{L}^{-1}$, and $10 \mathrm{mg}$ of the CMC/P(NIPAM-co-AA) hydrogel, the maximum adsorption capacity was $14.69 \mathrm{mg} \mathrm{g}^{-1}$. The kinetics fitted perfectly with the pseudo-second-order model, and the isotherms for the composite hydrogel adsorption of $\mathrm{U}(\mathrm{VI})$ was in accordance with the Langmuir model. The chemical modification confirmed that the acylamino group played an important role in uranium adsorption. The desorption and reusability study revealed that the resolution rate was still available at approximately $77.74 \%$ after five alternate heating cycles at 20 and $50{ }^{\circ} \mathrm{C}$ of adsorption-desorption.
\end{abstract}

Keywords: orthogonal experiments; U(VI); thermo-sensitive hydrogel; adsorption; wastewater treatment

\section{Introduction}

The technology of dissolution and leaching is widely used in uranium mining and metallurgy, and a large amount of low-concentration uranium-containing radioactive wastewater can be generated from these industrial processes, which could pose a serious potential risk to the environment and the health of those involved [1]. Traditional methods such as reverse osmosis, ion exchange, and evaporation have the demerits of complexity, high energy consumption, and cumbersome operation [2,3]. The adsorption method, which possesses the characteristics of a wide source of materials, low cost, high selectivity, fast treatment rate, and large capacity would provide a possibility for the efficient uptake of uranium-bearing wastewater [4]. However, adsorbents are usually difficult to 
regenerate and have poor reusability. Recently, "smart" hydrogels have attracted much interest in the treatment of wastewater contaminated with heavy metals. These "smart" hydrogels are characterized by their high expansion capacity, biocompatibility, reversibility, and maneuverability compared with traditional methods [5,6]. The intelligent responsiveness of hydrogels means that they are "smart" soft materials with three-dimensional cross-linked network structures that can change volume/shape or phase in sensitive response to environmental stimulation including temperature, $\mathrm{pH}$, magnetic field, electric field, light, and chemical substances [7-11]. The response characteristics of "smart" hydrogels are important parameters for their wide application in the fields of drug control release and separation, heavy metal adsorption, and biomedical treatments $[5,12,13]$.

Poly(N-isopropylacrylamide) (PNIPAM) is the most representative temperature-sensitive polymer. It undergoes an abrupt reversible phase transition near the lower critical solution temperature (LCST), exhibiting a dramatic volume change from the swollen network to the shrunken state by expelling free water $[14,15]$. Even though the PNIPAM hydrogel shows intelligent thermal sensitivity, which is beneficial for the treatment of wastewater containing heavy metals, it exhibits a low capacity of adsorption for metal ions. The presence of functional groups within polymer networks helps in binding heavy metals via the formation of complex structures [16]. Ju et al. [17] prepared poly(N-isopropylacrylamide-co-benzo-18-crown-6-acrylamide) (P(NIPAM-co-BCAm)) hydrogel by crosslinking the ether group with NIPAM. The P(NIPAM-co-BACm) hydrogel adsorbed $\mathrm{Pb}^{2+}$ at a temperature lower than the LCST and desorbed $\mathrm{Pb}^{2+}$ at a temperature higher than the LCST. The calic-conjugated thermo-responsive poly(N-isopropylacrylamide-co-tetra(5-hexenyloxy)-p-tertbutylcalix [4]arene) (P (NIPAM-co-HBCalix)) has also been manufactured for capturing $\mathrm{Ni}^{2+}$, and its adsorption capacity was maintained above $90 \%$ after five cycles of adsorption-desorption [18].

Carboxymethyl cellulose (CMC) is a degradation and biocompatibility biomass material containing a large amount of carboxyl oxygen and lone pair electrons in coordinated bonds that form chelates with metal ions [19-21]. Chen et al. [22] produced a bio-based adsorbent consisting of polyacrylamide, polyacrylic acid, and CMC (CMC-PAMA) by the thermal crosslinking of sodium carboxymethylcellulose, polyacrylic acid, and polyacrylamide with good stability and recyclability, whose static adsorption capacities for methylene blue (MB) and $\mathrm{Pb}(\mathrm{II})$ were, respectively, $1611.44 \mathrm{mg} \cdot \mathrm{g}^{-1}$ and $840.11 \mathrm{mg} \cdot \mathrm{g}^{-1}$. Sun et al. [23] applied biomaterials (CMC/gelatin/starch) to stabilize FeS nanoparticles for the removal of $\mathrm{Hg}$ (II). The experiments showed that the three biomaterial-stabilized nanoparticles could improve the adsorption efficiency significantly. Among those CMC-based polymers, the interactions of the $\mathrm{OH}$ group and metal ions would contribute to improve the stability and insolubility of water, which is conducive to the separation of metal ions from water after adsorption [16].

Our experiments aimed to use N-isopropylacrylamide (NIPAM) as a matrix to prepare a temperature sensitive intelligent hydrogel. During gel preparation, polymerization parameters such as polymerization temperature, the ratio of crosslinker to monomer, and the type of polymer composition could contribute to the desirable properties of thermo-sensitive hydrogels [24]. Even though the polymers of NIPAM, CMC, and acrylic acid (AA) in Na-montmorillonite (MMT) have been fabricated [25], the principal element of preparation of thermo-sensitive hydrogel and the influence mechanism are still unclear. Moreover, temperature-sensitive hydrogels prepared by pre-experiment were fragile after the adsorption of water, which did not meet the reusability demands of uranium removal. Therefore, we have attempted to optimize the synthesis condition for the CMC/P (NIPAM-co-AA) hydrogel through L16 $\left(4^{5}\right)$ orthogonal experiments and determine the dominant factor in the polymerization. The chemical structure, thermostability, and morphology have been represented by a series of characterizations. The behaviors of composite hydrogel adsorption of $\mathrm{U}(\mathrm{VI})$, including adsorption kinetics, isotherms, thermodynamics, and reusability performance, were systematically investigated. 


\section{Materials and Methods}

\subsection{Materials}

The main materials for the preparation of thermo-sensitive hydrogels of CMC/P (NIPAM-co-AA) include NIPAM, AA, CMC, N,N-methylene bis acrylamide (BIS), ammonium persulphate (APS), and $\mathrm{N}, \mathrm{N}, \mathrm{N}^{\prime}, \mathrm{N}^{\prime}$-tetramethylethylenediamine (TEMED). The sources of these reagents/materials are shown in Table 1. Among them, $\mathrm{N}$-isopropyl acrylamide was recrystallized three times in $\mathrm{n}$-hexane; the rest of the materials were of analytical purity.

Table 1. List of the main materials for the preparation of the temperature sensitive hydrogel.

\begin{tabular}{cc}
\hline Materials & Manufacturer \\
\hline N-isopropylacrylamide (NIPAM) & $\begin{array}{c}\text { Chengdu Aikeda Chemical Reagent Co., Ltd. } \\
\text { (Chengdu, China) }\end{array}$ \\
\hline acrylic acid (AA) & Aladdin Reagent Co., Ltd. (Shanghai, China) \\
\hline Carboxymethyl cellulose (CMC) & $\begin{array}{c}\text { Shanghai shanpu chemical Co., Ltd. } \\
\text { (Shanghai, China) }\end{array}$ \\
\hline $\mathrm{N}, \mathrm{N}$-methylene bis acrylamide (BIS) & $\begin{array}{c}\text { Tianjin Kemiou Chemical Reagent Co., Ltd. } \\
\text { (Tianjin, China) }\end{array}$ \\
\hline Ammonium persulfate (APS) & Xilong Chemical Co., Ltd. (Guangdong, China) \\
\hline $\mathrm{N}, \mathrm{N}, \mathrm{N}^{\prime}, \mathrm{N}^{\prime}$-tetramethylethylenediamine (TEMED) & Tixiai Chemical Industry Development Co., Ltd. \\
(Shanghai, China)
\end{tabular}

\subsection{Preparation of CMC/P (NIPAM-co-AA) Hydrogels by Orthogonal Experiments}

The L16 $\left(4^{5}\right)$ orthogonal experiments were designed for the optimization of the synthesis condition. Intelligent hydrogels were made by free radical polymerization. Recrystallization NIPAM, AA, BIS (crosslinking agent), and CMC (0.6 g of each) were added in sequence to three flasks containing $10 \mathrm{~mL}$ of deionized water under the nitrogen gas condition, which was well mixed using an electric mixer. After half an hour of continuously admitting the nitrogen gas to the reaction flasks, the reaction was initiated in the presence of APS (initiator) and TEMED (catalyst), then the mixture was quickly transferred to a cylindrical sealed tube and placed in a water bath for $24 \mathrm{~h}$ at a temperature of $0,25,35$ and $70{ }^{\circ} \mathrm{C}$ to prepare the hydrogel.

After polymerization, the composite hydrogel was washed in deionized water over a $48 \mathrm{~h}$ period to remove the unreacted polymer monomer, changing the water every $12 \mathrm{~h}$. Finally, the hydrogel was sliced then vacuum freeze-dried over $24 \mathrm{~h}$. The addition amounts of each polymer monomer are shown in Tables 2 and 3.

Table 2. Level factor of the orthogonal experiment.

\begin{tabular}{cccccc}
\hline Level & $\mathbf{A}(\mathbf{C M C} / \mathbf{g})$ & $\mathbf{B}(\mathbf{A A} / \mathbf{g})$ & $\mathbf{C}(\mathbf{A P S} / \mathbf{g})$ & $\mathbf{D}(\mathrm{BIS} / \mathrm{g})$ & $\mathbf{E}($ Temperature/ \\
\hline
\end{tabular}


Table 3. Arrangements of the 5-variable 4-level orthogonal experiment.

\begin{tabular}{|c|c|c|c|c|c|}
\hline $\mathrm{L}_{16}\left(4^{5}\right)$ & (A) $\mathrm{CMC} / \mathrm{g}$ & (B) $\mathrm{AA} / \mathrm{g}$ & (C) Initiator/g & (D) Crosslinker/g & (F) Temperature/ ${ }^{\circ} \mathrm{C}$ \\
\hline 1 & $\mathrm{~A}_{1} 0.05$ & $\mathrm{~B}_{1} 0.05$ & $C_{1} 0.02$ & $\mathrm{D}_{1} 0.01$ & $\mathrm{E}_{1} 0$ \\
\hline 2 & $\mathrm{~A}_{1} 0.05$ & $\mathrm{~B}_{2} 0.1$ & $\mathrm{C}_{2} 0.04$ & $\mathrm{D}_{2} 0.03$ & $E_{2} 25$ \\
\hline 3 & $\mathrm{~A}_{1} 0.05$ & $\mathrm{~B}_{3} 0.15$ & $\mathrm{C}_{3} 0.06$ & $\mathrm{D}_{3} 0.05$ & $E_{3} 35$ \\
\hline 4 & $\mathrm{~A}_{1} 0.05$ & $\mathrm{~B}_{4} 0.2$ & $\mathrm{C}_{4} 0.08$ & $\mathrm{D}_{4} 0.07$ & $\mathrm{E}_{4} 70$ \\
\hline 5 & $\mathrm{~A}_{2} 0.1$ & $\mathrm{~B}_{1} 0.05$ & $\mathrm{C}_{2} 0.04$ & $\mathrm{D}_{3} 0.05$ & $\mathrm{E}_{4} 70$ \\
\hline 6 & $\mathrm{~A}_{2} 0.1$ & $\mathrm{~B}_{2} 0.1$ & $\mathrm{C}_{1} 0.02$ & $\mathrm{D}_{4} 0.07$ & $E_{3} 35$ \\
\hline 7 & $\mathrm{~A}_{2} 0.1$ & $\mathrm{~B}_{3} 0.15$ & $\mathrm{C}_{4} 0.08$ & $\mathrm{D}_{1} 0.01$ & $E_{2} 25$ \\
\hline 8 & $\mathrm{~A}_{2} 0.1$ & $\mathrm{~B}_{4} 0.2$ & $C_{3} 0.06$ & $\mathrm{D}_{2} 0.03$ & $\mathrm{E}_{1} 0$ \\
\hline 9 & $\mathrm{~A}_{3} 0.2$ & $\mathrm{~B}_{1} 0.05$ & $\mathrm{C}_{3} 0.06$ & $\mathrm{D}_{4} 0.07$ & $E_{2} 25$ \\
\hline 10 & $\mathrm{~A}_{3} 0.2$ & $\mathrm{~B}_{2} 0.1$ & $\mathrm{C}_{4} 0.08$ & $\mathrm{D}_{3} 0.05$ & $\mathrm{E}_{1} 0$ \\
\hline 11 & $\mathrm{~A}_{3} 0.2$ & $\mathrm{~B}_{3} 0.15$ & $C_{1} 0.02$ & $\mathrm{D}_{2} 0.03$ & $\mathrm{E}_{4} 70$ \\
\hline 12 & $\mathrm{~A}_{3} 0.2$ & $\mathrm{~B}_{4} 0.2$ & $\mathrm{C}_{2} 0.04$ & $\mathrm{D}_{1} 0.01$ & $E_{3} 35$ \\
\hline 13 & $\mathrm{~A}_{4} 0.3$ & $\mathrm{~B}_{1} 0.05$ & $\mathrm{C}_{4} 0.08$ & $\mathrm{D}_{2} 0.03$ & $E_{3} 35$ \\
\hline 14 & $\mathrm{~A}_{4} 0.3$ & $\mathrm{~B}_{2} 0.1$ & $\mathrm{C}_{3} 0.06$ & $\mathrm{D}_{1} 0.01$ & $\mathrm{E}_{4} 70$ \\
\hline 15 & $\mathrm{~A}_{4} 0.3$ & $\mathrm{~B}_{3} 0.15$ & $\mathrm{C}_{2} 0.04$ & $\mathrm{D}_{4} 0.07$ & $\mathrm{E}_{1} 0$ \\
\hline 16 & $\mathrm{~A}_{4} 0.3$ & $\mathrm{~B}_{4} 0.2$ & $\mathrm{C}_{1} 0.02$ & $\mathrm{D}_{3} 0.05$ & $E_{2} 25$ \\
\hline
\end{tabular}

\subsection{Index Test of Orthogonal Experiments}

\subsubsection{Swelling Behavior of Composite Hydrogel}

The water absorption rate (SR) of the CMC/P-(NIPAM-co-AA) hydrogel was determined by the tea-bag method [26]. Composite hydrogel samples were accurately weighed after drying through vacuum freezing in the freeze dryer (FD5-series, SIM). The mass of the dried hydrogel samples were recorded as $W_{\mathrm{g}}$. The dry gel was placed in empty tea-bags of $5 \mathrm{~cm} \times 6 \mathrm{~cm}$, which was made of plant fiber. The samples in the tea-bags were then immersed in a buffer solution of $\mathrm{pH}=2$ for $24 \mathrm{~h}$. The data was recorded to obtain the mass of the hydrogel after absorbing water as $W_{\mathrm{s}}$. The water adsorption ratio $(S R)$ of the composite hydrogel was calculated as follows:

$$
S R(\%)=\frac{W_{s}-W_{g}}{W_{g}}
$$

\subsubsection{Adsorption Capacity of Uranium}

The adsorption capacity of uranium was determined by immersing the $10 \mathrm{mg}$ hydrogel in $30 \mathrm{mg} \mathrm{L}^{-1}$ $\mathrm{U}(\mathrm{VI})$ solutions at $\mathrm{pH}=6$ and a temperature of $298 \mathrm{~K}$ for $2 \mathrm{~h}$. The adsorption uptake amount of U(VI) by the hydrogel $\left(q_{\mathrm{e}}, \mathrm{mg} \cdot \mathrm{g}^{-1}\right)$ and the removal rate $(\eta, \%)$ were determined by Equations (2) and (3), respectively, as follow:

$$
\begin{gathered}
q_{e}=\frac{\left(C_{0}-C_{t}\right) V}{m} \\
\eta=\frac{\left(C_{0}-C_{t}\right)}{C_{0}} \times 100 \%
\end{gathered}
$$

where $C_{0}\left(\mathrm{mg} \cdot \mathrm{L}^{-1}\right)$ and $C_{\mathrm{t}}\left(\mathrm{mg} \cdot \mathrm{L}^{-1}\right)$ represent the initial concentration and equilibrated concentration of $\mathrm{U}(\mathrm{VI})$, and $\mathrm{m}(\mathrm{g})$ and $\mathrm{V}(\mathrm{mL})$ are the mass of the hydrogel and the volume of the solution, respectively.

\subsubsection{Study on the Structure and Thermal Stability of Gel}

The structure of hybrid hydrogels was confirmed by the Fourier-transform infrared (FTIR) spectra of a Nicolet-460 spectrometer (Nicolet, Madison, WI, USA) from the wavenumber range of 400 to $4000 \mathrm{~cm}^{-1}$. The thermal stability of the gels was performed by thermogravimetric analysis (TGA) in the temperature range of $30-600^{\circ} \mathrm{C}$ with dried gel on a DSC 200-F3 (Netzsch, Bavaria, Germany). 


\subsection{Batch Sorption Experiments}

The evaluation of the adsorption properties of the CMC/P (NIPAM-co-AA) hydrogel for the uptake of U(VI) was carried out. Different concentrations of the U(VI) solution ( $30 \mathrm{~mL}$ of each) were shaken on a shaking table at $150 \mathrm{rpm}$ so that proper reaction could take place with a constant temperature and $\mathrm{pH}$ value. The $\mathrm{pH}$ value was regulated by $\mathrm{HCl}$ and $\mathrm{NaOH}$ solutions. The solid-liquid separation was then done by filtration. The uranium concentration in the remaining solution was determined by spectrophotometry (WFJ 2000, Unic, Shanghai, China).

\subsection{Mechanism Analysis of Adsorption on U(VI)}

\subsubsection{Characterization}

The CMC/P (NIPAM-co-AA) hydrogel, before and after the adsorption of U(VI), was characterized by scanning electron microscopy (SEM), mercury intrusion porosimetry (MIP), and X-ray photoelectron spectroscopy (XPS). The SEM images were obtained by a JSM-7500F SEM instrument (JEOL, Akishima, Japan) after quenching in liquid nitrogen. The pore size of the hydrogel before and after U(VI)-loading were examined by MIP AutoPore IV (Micromeritics, Norcross, GA, USA). XPS spectra were acquired on an Escalab 250Xi (Thermo Fisher Scientific, Waltham, MA, USA).

\subsubsection{Chemical Modification of the Hydrogel}

In order to examine the functional groups that play a major role in the adsorption of U(VI), the surface of the hydrogel was treated in series with methyl alcohol and concentrated hydrochloric acid to shield the carboxyl group, and then with formaldehyde to mask the hydroxyl group [27,28].

Ten milligrams of hydrogel was mixed with $20 \mathrm{~mL}$ of methyl alcohol and $0.2 \mathrm{~mL}$ of concentrated hydrochloric acid at $20{ }^{\circ} \mathrm{C}$ in a reaction flask and was then shaken on a shaking table for $8 \mathrm{~h}$. Ten milligrams of hydrogel was immersed in $10 \mathrm{~mL}$ of formaldehyde under the same condition for $8 \mathrm{~h}$. Ten milligrams of the hydrogel was added into the mixture of $20 \mathrm{~mL}$ of formic acid and $10 \mathrm{~mL}$ of formaldehyde to shield the amide group. Then, after treatment, the hydrogels were all washed three times with distilled water and were added to $5 \mathrm{mg} \mathrm{L}^{-1} \mathrm{U}(\mathrm{VI})$ solution for $1 \mathrm{~h}$ of adsorption reaction. The remaining U(VI) solution was measured by spectrophotometry (WFJ 2000, Unic, Shanghai, China), as mentioned above.

\subsection{Desorption and Recycling Experiment}

The hydrogel was placed under optimal adsorption conditions to achieve adsorption equilibrium and was washed three times with distilled water. The desorption of U(VI) from the hydrogel was monitored by placing the hydrogel in $0.1 \mathrm{~mol} \mathrm{~L}^{-1}$ of $\mathrm{HNO}_{3}$ solution at different temperatures, where it was left for between $10 \mathrm{~min}$ and $5 \mathrm{~h}$.

The regeneration ability of the hydrogel was evaluated by conducting a heating cycle of adsorption-desorption. The alternated adsorption-desorption cycles were repeated five times at 20 and $50^{\circ} \mathrm{C}$. The remaining $\mathrm{U}(\mathrm{VI})$ concentration in the solution was determined by spectrophotometry.

\section{Results and Discussion}

\subsection{Results and Range Analysis of Orthogonal Experiments}

The results of the 5-variable 4-level orthogonal experiment are shown in Table 4. The water adsorption ratio $(S R)$ and $\mathrm{U}(\mathrm{VI})$ removal rate $(\eta)$ were the two test indexes. This study used a comprehensive scoring method. The results of the range analysis in this orthogonal experiment are shown in Table 5. From the results, the order of the main influencing factors for preparing hydrogels is: polymerization temperature $>$ the dosage of $\mathrm{AA}>$ the dosage of $\mathrm{CMC}>$ the amount of cross-linker $>$ the amount of Initiator. The best combination of mechanical properties and uranium adsorption 
properties was $\mathrm{A}_{2} \mathrm{~B}_{3} \mathrm{C}_{3} \mathrm{D}_{2} \mathrm{E}_{1}$, which was $0.1 \mathrm{~g}$ of $\mathrm{CMC}, 0.15 \mathrm{~g}$ of $\mathrm{AA}, 0.06 \mathrm{~g}$ of initiator, and $0.03 \mathrm{~g}$ of cross-linker at the polymerization temperature of $0{ }^{\circ} \mathrm{C}$.

Table 4. Results of the 5-variable 4-level orthogonal experiment.

\begin{tabular}{|c|c|c|c|c|c|c|c|}
\hline \multirow[b]{2}{*}{$\mathrm{L}_{16}\left(4^{5}\right)$} & \multirow[b]{2}{*}{ A } & \multirow[b]{2}{*}{ B } & \multirow[b]{2}{*}{ C } & \multirow[b]{2}{*}{ D } & \multirow[b]{2}{*}{$\mathbf{F}$} & \multicolumn{2}{|c|}{ Test Index } \\
\hline & & & & & & $\begin{array}{c}\text { Water Adsorption } \\
\text { Ratio (SR) }\end{array}$ & $\begin{array}{c}\text { U(VI) Removal } \\
\text { Rate }(\eta)\end{array}$ \\
\hline 1 & $\mathrm{~A}_{1}$ & $\mathrm{~B}_{1}$ & $\mathrm{C}_{1}$ & $\mathrm{D}_{1}$ & $\mathrm{E}_{1}$ & 41 & 82.7 \\
\hline 2 & $\mathrm{~A}_{1}$ & $\mathrm{~B}_{2}$ & $\mathrm{C}_{2}$ & $\mathrm{D}_{2}$ & $\mathrm{E}_{2}$ & 13 & 94.2 \\
\hline 3 & $\mathrm{~A}_{1}$ & $\mathrm{~B}_{3}$ & $\mathrm{C}_{3}$ & $\mathrm{D}_{3}$ & $\mathrm{E}_{3}$ & 37 & 86.9 \\
\hline 4 & $\mathrm{~A}_{1}$ & $\mathrm{~B}_{4}$ & $\mathrm{C}_{4}$ & $\mathrm{D}_{4}$ & $\mathrm{E}_{4}$ & 3 & 4.1 \\
\hline 5 & $\mathrm{~A}_{2}$ & $\mathrm{~B}_{1}$ & $C_{2}$ & $\mathrm{D}_{3}$ & $\mathrm{E}_{4}$ & 22 & 94.7 \\
\hline 6 & $\mathrm{~A}_{2}$ & $\mathrm{~B}_{2}$ & $\mathrm{C}_{1}$ & $\mathrm{D}_{4}$ & $\mathrm{E}_{3}$ & 25 & 93.6 \\
\hline 7 & $\mathrm{~A}_{2}$ & $\mathrm{~B}_{3}$ & $\mathrm{C}_{4}$ & $\mathrm{D}_{1}$ & $E_{2}$ & 21 & 92.3 \\
\hline 8 & $\mathrm{~A}_{2}$ & $\mathrm{~B}_{4}$ & $C_{3}$ & $\mathrm{D}_{2}$ & $\mathrm{E}_{1}$ & 50 & 97.3 \\
\hline 9 & $\mathrm{~A}_{3}$ & $\mathrm{~B}_{1}$ & $C_{3}$ & $\mathrm{D}_{4}$ & $\mathrm{E}_{2}$ & 12 & 92.8 \\
\hline 10 & $\mathrm{~A}_{3}$ & $\mathrm{~B}_{2}$ & $\mathrm{C}_{4}$ & $\mathrm{D}_{3}$ & $\mathrm{E}_{1}$ & 18 & 92.7 \\
\hline 11 & $\mathrm{~A}_{3}$ & $\mathrm{~B}_{3}$ & $C_{1}$ & $\mathrm{D}_{2}$ & $\mathrm{E}_{4}$ & 28 & 16.4 \\
\hline 12 & $\mathrm{~A}_{3}$ & $\mathrm{~B}_{4}$ & $\mathrm{C}_{2}$ & $\mathrm{D}_{1}$ & $\mathrm{E}_{3}$ & 4 & 42.3 \\
\hline 13 & $\mathrm{~A}_{4}$ & $\mathrm{~B}_{1}$ & $\mathrm{C}_{4}$ & $\mathrm{D}_{2}$ & $\mathrm{E}_{3}$ & 37 & 85.9 \\
\hline 14 & $\mathrm{~A}_{4}$ & $\mathrm{~B}_{2}$ & $\mathrm{C}_{3}$ & $\mathrm{D}_{1}$ & $\mathrm{E}_{4}$ & 25 & 37.0 \\
\hline 15 & $\mathrm{~A}_{4}$ & $\mathrm{~B}_{3}$ & $\mathrm{C}_{2}$ & $\mathrm{D}_{4}$ & $\mathrm{E}_{1}$ & 43 & 94.9 \\
\hline 16 & $\mathrm{~A}_{4}$ & $\mathrm{~B}_{4}$ & $\mathrm{C}_{1}$ & $\mathrm{D}_{3}$ & $\mathrm{E}_{2}$ & 12 & 92.1 \\
\hline
\end{tabular}

Table 5. Range analysis of the L16 $\left(4^{5}\right)$ experimental results.

\begin{tabular}{cccccc}
\hline Analysis & A & B & C & D & E \\
\hline$\overline{K_{1}}$ & 24.325 & 29.150 & 27.300 & 23.275 & 38.975 \\
$\overline{K_{2}}$ & 30.475 & 21.000 & 21.375 & 32.950 & 15.375 \\
$\overline{K_{3}}$ & 16.100 & 32.925 & 31.675 & 23.175 & 26.425 \\
$\overline{K_{4}}$ & 30.025 & 17.850 & 20.575 & 21.525 & 20.150 \\
$\mathrm{R}$ & 14.375 & 15.075 & 11.100 & 11.425 & 23.600 \\
Optimal level & $\mathbf{A}_{\mathbf{2}}$ & $\mathbf{B}_{\mathbf{3}}$ & $\mathbf{C}_{\mathbf{3}}$ & $\mathbf{D}_{\mathbf{2}}$ & $\mathbf{E}_{\mathbf{1}}$ \\
\hline
\end{tabular}

\subsection{Characterization of FTIR and TGA for Gel}

Crosslinked network hydrogels are divided into two categories, one is the semi-interpenetrating network (semi-IPN) hydrogel and the other is the interpenetrating network (IPN) hydrogel. The CMC/P (NIPAM-co-AA) hydrogel belongs to the latter. The first layer of the crosslinked network is formed by polymerization, while carboxymethyl cellulose is used as the second layer of the crosslinked network by hydrogen bonding and Van der Waals interactions [29,30]. Figure 1 shows the proposed schematic diagram of the fabrication process of the CMC/P (NIPAM-co-AA) hydrogel [31]. The first network was the formation of the integration of NIPAM and AA, with APS as an initiator; BIS is a cross-linker (a). CMC was immersed in the mixture of the first crosslinked network (b). Finally, the IPN hydrogel was incorporated through the polymerization reaction at $0{ }^{\circ} \mathrm{C}$ (c). The photographs of the CMC/P (NIPAM-Co-AA) hydrogel after infusion in deionized water at 20 and $60^{\circ} \mathrm{C}$ are shown in Figure 2. The IPN hydrogel at $20^{\circ} \mathrm{C}$ was translucent in comparison to the hydrogel at $60^{\circ} \mathrm{C}$. There was a very significant discrepancy in the swelling capacity of the gel between 20 and $60^{\circ} \mathrm{C}$. The volume change confirmed the temperature sensitivity of the gel, thus demonstrating the successful synthesis of IPN gels. 


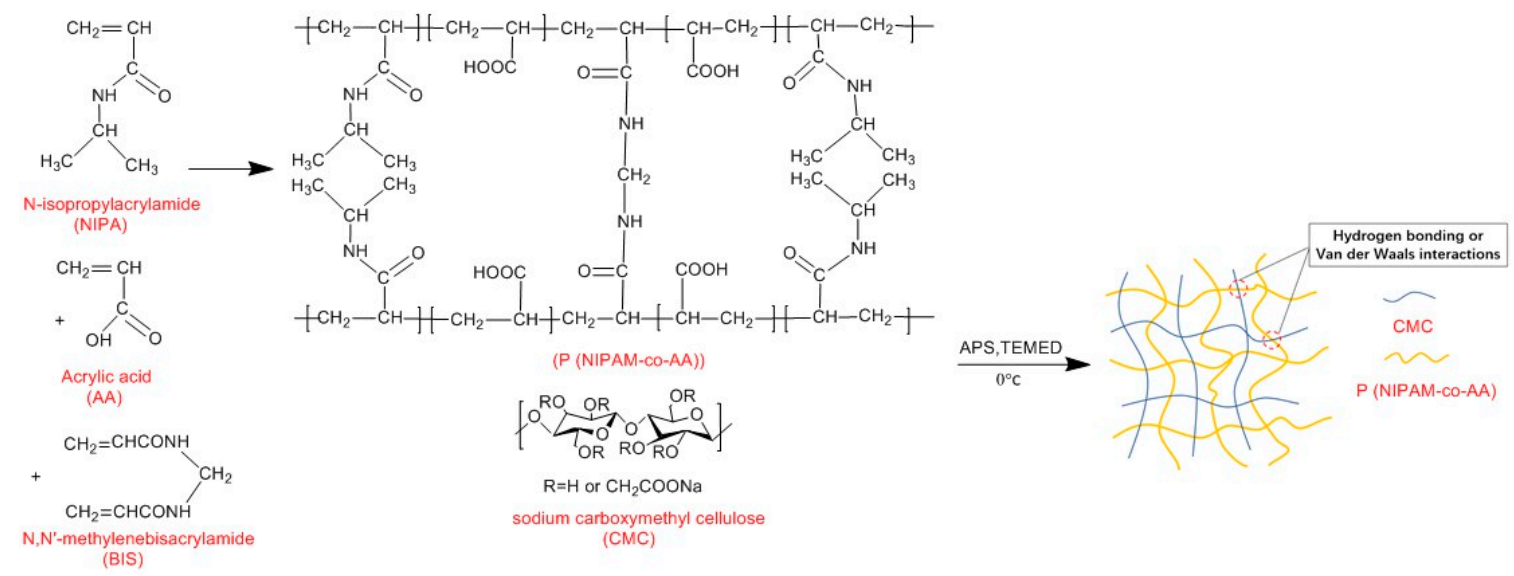

Figure 1. Proposed fabrication process of the CMC/P (NIPAM-co-AA) hydrogel.

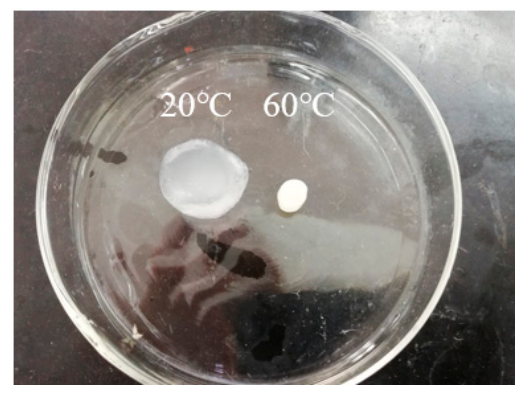

Figure 2. Photographs of the interpenetrating network (IPN) hydrogel after infusion in deionized water at 20 and $60^{\circ} \mathrm{C}$.

In order to further confirm the IPN crosslinking structure of the gel, the FTIR spectra of CMC, the PNIPAM hydrogel, and CMC/P (NIPAM-co-AA) are presented in Figure 3. (1) In the CMC FTIR spectrum, the absorption peaks at 1608 and $1422 \mathrm{~cm}^{-1}$ were symmetric and asymmetric stretching vibrations of the carbonyl group of carboxylic acid, respectively [32]. The adsorption peaks at 1326 and $1114 \mathrm{~cm}^{-1}$ belong to the stretching vibration and non-stretching vibration of $\mathrm{C}-\mathrm{O}-\mathrm{C}$ of the cellulose ether bond, while that at $3446 \mathrm{~cm}^{-1}$ was from the hydrogen bond with a wide absorption peak [33]. (2) In the FTIR spectrum of the PNIPAM hydrogel, $1639 \mathrm{~cm}^{-1}$ indicated the telescopic vibration of C=O of the amide group, $1387 \mathrm{~cm}^{-1}$ and $1368 \mathrm{~cm}^{-1}$ were the characteristic bimodal of isopropyl of NIPAM, which were the $\mathrm{C}-\mathrm{H}$ symmetric bending vibration peaks of two methyl groups. The absorption peak of $3444 \mathrm{~cm}^{-1}$ was related to the $\mathrm{N}-\mathrm{H}$ telescopic vibration. (3) In the curve of the CMC/P (NIPAM-co-AA) hydrogel, the absorption peak of $3449 \mathrm{~cm}^{-1}$ is much sharper and narrower in comparison to the $3444 \mathrm{~cm}^{-1}$ of the PNIPAM spectrum. This is possibly due to the synthesis of the acrylic acid containing $\mathrm{O}-\mathrm{H}$ group and the covering portion of the $\mathrm{N}-\mathrm{H}$ peak. At the same time, the peak at $1634 \mathrm{~cm}^{-1}$ was the interaction of the bending vibration of $\mathrm{C}=\mathrm{O}$ and the stretching vibration of $\mathrm{N}-\mathrm{H}$. Meanwhile, the peak of the $\mathrm{C}-\mathrm{O}-\mathrm{C}$ of $\mathrm{CMC}$ and the isopropyl characteristic peak of PNIPAM basically disappeared in the curve of the CMC/P (NIPAM-co-AA) hydrogel due to the formation of the cross-linking network between the chain of CMC and the polymerase chain of $\mathrm{P}$ (NIPAM-co-AA). Therefore, the spectra have illustrated the successful linking of CMC onto the P (NIPAM-co-AA) polymer [34]. 


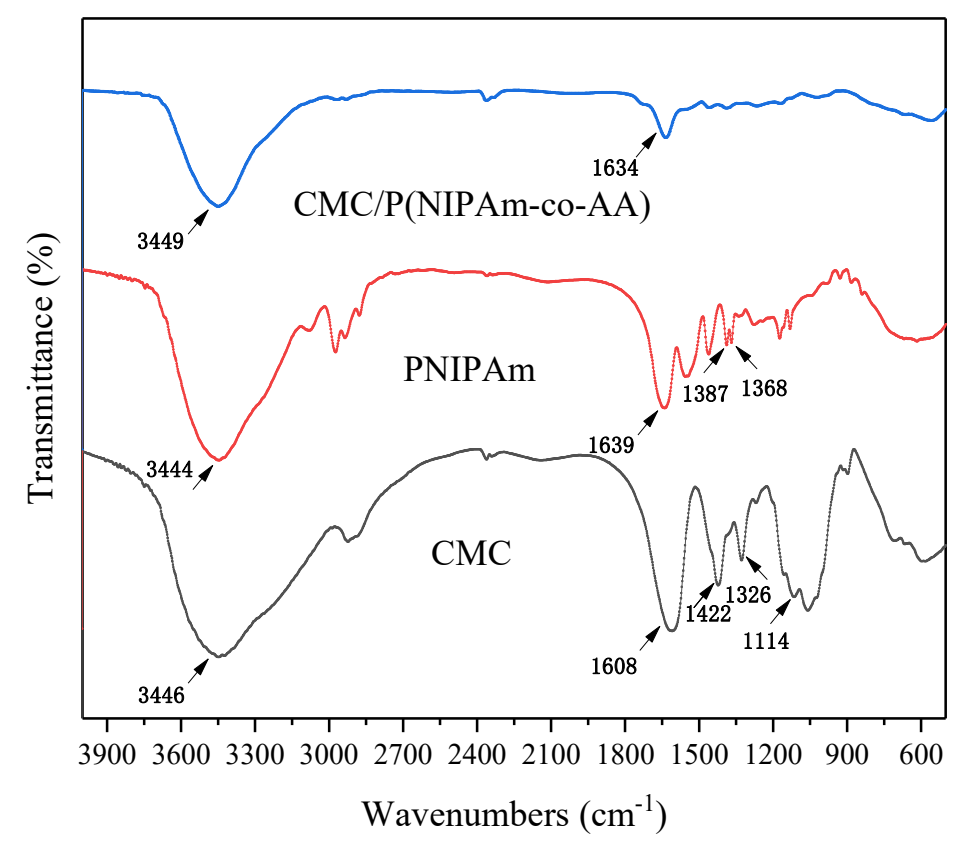

Figure 3. FTIR spectrum of CMC, PNIPAM, and CMC/P (NIPAM-CO-AA).

The thermogravimetric (TGA) curves of PNIPAM, P (NIPAM-co-AA), P (NIPAM-co-CMC), and $\mathrm{CMC} / \mathrm{P}$ (NIPAM-co-AA) are presented in Figure 4. The thermal decomposition of P (NIPAM-co-AA), $\mathrm{P}$ (NIPAM-co-CMC), and CMC/P (NIPAM-co-AA) is mainly divided into three stages, each with elevated temperatures. The first stage is $50-100{ }^{\circ} \mathrm{C}$ and is due to the residual water evaporation. The second stage is $100-370{ }^{\circ} \mathrm{C}$ and is mainly due to the fracture and digestion of the terminal and side chain functional groups. Meanwhile, CMC/P (NIPAM-co-AA) was shown to have a large amount of weightlessness in the second stage, indicating that its polymerization chain was fractured and the digestion was more numerous than in the other two materials. The third stage is due to the degradation of the polymerase chain of NIPAM at $370-550^{\circ} \mathrm{C}$. The thermal decomposition of PNIPAM involves only two stages, which are residual water evaporation and self-degradation [35].

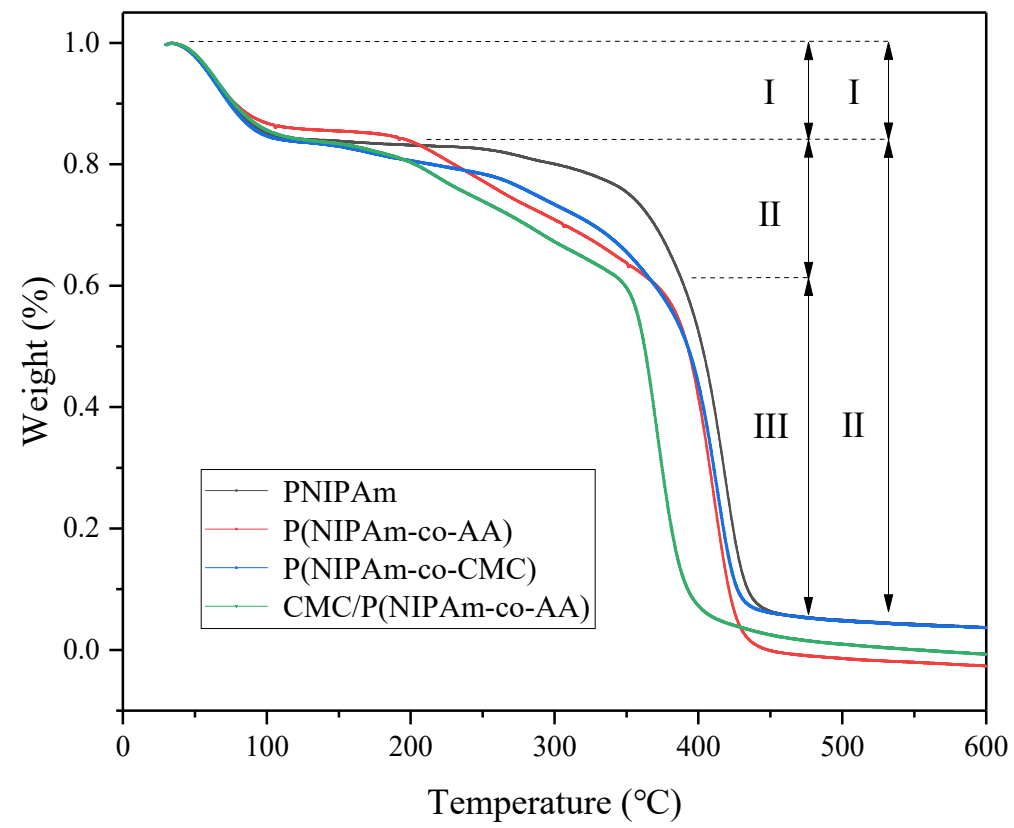

Figure 4. Thermogravimetric (TGA) curves of P-NIPAM, P (NIPAM-co-AA), P (NIPAM-co-CMC), and $\mathrm{CMC} / \mathrm{P}(\mathrm{NIPAM}-\mathrm{CO}-\mathrm{AA})$ at a heating rate of $10^{\circ} \mathrm{C} \cdot \mathrm{min}^{-1}$. 


\subsection{Adsorption Performance of $U(V I)$ under Different Conditions}

\subsubsection{The Contact Time and Adsorption Kinetics Analysis}

The effect of contact time on the U(VI) adsorption by CMC/P (NIPAM-co-AA) and PNIPAM were evaluated by carrying out an experiment under the reaction of $\mathrm{pH}=6$ and a temperature of 298 $\mathrm{K}$, an initial concentration of $\mathrm{U}(\mathrm{VI})$ of $5 \mathrm{mg} \mathrm{L}^{-1}$, and $10 \mathrm{mg}$ of PNIPAM or CMC/P (NIPAM-co-AA), in the range of 5-240 $\mathrm{min}$. The results are shown in Figure 5. The adsorption capacity of the PNIPAM hydrogel for $\mathrm{U}(\mathrm{VI})$ was barely immutable over time, which indicates that the adsorption of uranium by the gel is time-independent. For the CMC/P (NIPAM-co-AA) hydrogel, the adsorption reaction reached equilibrium after one hour.

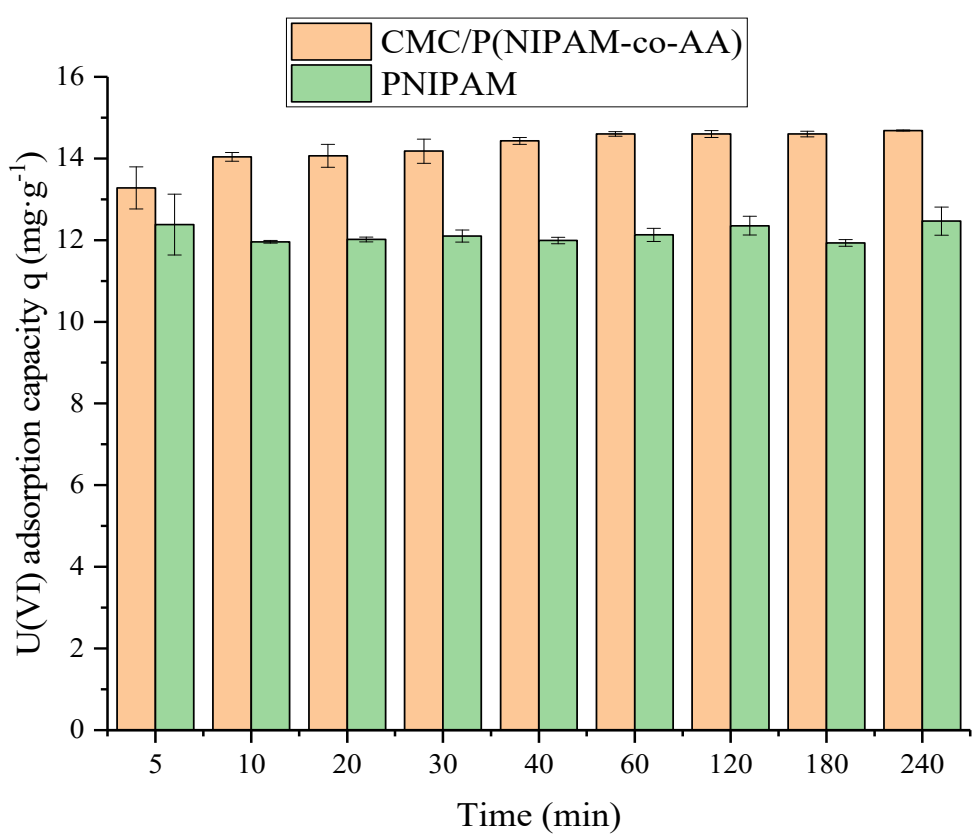

Figure 5. Effect of reaction time on U(VI) adsorption by CMC/P (NIPAM-co-AA) and PNIPAM.

The kinetics of the adsorption of U(VI) by PNIPAM and CMC/P (NIPAM-co-AA) were evaluated by a pseudo-first-order kinetic model, Equation (4), and a pseudo-second-order kinetic model, Equation (5), respectively.

$$
\begin{gathered}
\operatorname{In}\left(q_{e}-q_{t}\right)=\operatorname{In} q_{e}-k_{1} t \\
\frac{t}{q_{t}}=\frac{1}{k_{2} \cdot q_{e}^{2}}+\frac{t}{q_{e}}
\end{gathered}
$$

where $q_{\mathrm{e}}\left(\mathrm{mg} \mathrm{g}^{-1}\right)$ and $q_{\mathrm{t}}\left(\mathrm{mg} \mathrm{g}^{-1}\right)$ represent the equilibrium adsorption quantity and the adsorption amount, respectively; $k_{1}$ and $k_{2}$ are the constant of the first-order adsorption rate and the second-order adsorption rate, respectively; and $\mathrm{t}(\mathrm{min})$ is the reaction time.

From Table 6, the correlation coefficient of $\mathrm{U}(\mathrm{VI})$ adsorption was matched by the pseudo-secondorder kinetic model, $R^{2}$, for PNIPAM and CMC/P (NIPAM-co-AA), which were 0.9993 and 1 , respectively. Moreover, the theoretical maximum adsorption by the pseudo-second-order kinetic model of $\mathrm{CMC} / \mathrm{P}$ (NIPAM-co-AA) was $14.71 \mathrm{mg} \mathrm{g}^{-1}$, which was much closer to the actual maximum adsorption capacity of $14.69 \mathrm{mg} \mathrm{g}^{-1}$. So was PNIPAM, whose theoretical maximum adsorption and actual maximum adsorption capacity were 12.32 and $12.47 \mathrm{mg} \mathrm{g}^{-1}$ by the pseudo-second-order kinetic model, respectively. Therefore, the adsorption process of U(VI) by PNIPAM and CMC/P (NIPAM-co-AA) conformed to the secondary dynamic adsorption model, which indicates that the adsorption rate is controlled by chemisorption [36]. 
Table 6. Kinetic parameters of adsorption of PNIPAM and CMC/P (NIPAM-co-AA) at 298 K.

\begin{tabular}{|c|c|c|c|c|c|c|c|}
\hline \multirow{2}{*}{ Material } & \multirow{2}{*}{$\underset{\left(\mathrm{mg} \cdot \mathrm{g}^{-1}\right)}{q_{e, \exp }}$} & \multicolumn{3}{|c|}{$\begin{array}{l}\text { Pseudo-First-Order } \\
\text { Kinetic Model }\end{array}$} & \multicolumn{3}{|c|}{$\begin{array}{l}\text { Pseudo-Second-Order } \\
\text { Kinetic Model }\end{array}$} \\
\hline & & $k_{1}$ & $q_{e \cdot c a l}$ & $\mathbf{R}^{2}$ & $k_{2}$ & $q_{e \cdot c a l}$ & $R^{2}$ \\
\hline PNIPAM & 12.47 & 0.0124 & 0.49 & 0.412 & 0.1181 & 12.32 & 0.9993 \\
\hline CMC/P (NIPAM-co-AA) & 14.69 & 0.0189 & 0.81 & 0.848 & 0.0922 & 14.71 & 1 \\
\hline
\end{tabular}

\subsubsection{Effect of $\mathrm{pH}$}

The effect of $\mathrm{pH}$ on the $\mathrm{U}(\mathrm{VI})$ adsorption was determined. Ten milligrams of $\mathrm{CMC} / \mathrm{P}$ (NIPAM-co-AA) or PNIPAM was added to an initial concentration of $5 \mathrm{mg} \mathrm{L}^{-1}$ of U(VI), under the reaction condition of $298 \mathrm{~K}$, at various $\mathrm{pH}$ values from 2.0 to 7.0 for $1 \mathrm{~h}$ of adsorption time. The results in Figure 6 show that the adsorption quantity of U(VI) by CMC/P (NIPAM-co-AA) is higher than by PNIPAM at a pH of 2.0 to 7.0, which illustrates that CMC and AA can promote the adsorption of $\mathrm{U}(\mathrm{VI})$ more efficiently. The increase in $\mathrm{pH}$ can cause a gradual corresponding increase in the adsorption capacity of CMC/P (NIPAM-co-AA) and PNIPAM. A plateau was reached at $\mathrm{pH}=4$. At low $\mathrm{pH}$ values, the excessive $\mathrm{H}^{+}$in the solution protonates the carboxyl group in the hydrogel, weakening the electrostatic attraction between the carboxyl group and the uranium ion. At the same time, the excess $\mathrm{H}^{+}$generates $\mathrm{H}_{3} \mathrm{O}^{+}$, which competes with the uranium ion for adsorption, thus affecting the $\mathrm{U}(\mathrm{VI})$ adsorption of the hydrogel [37].

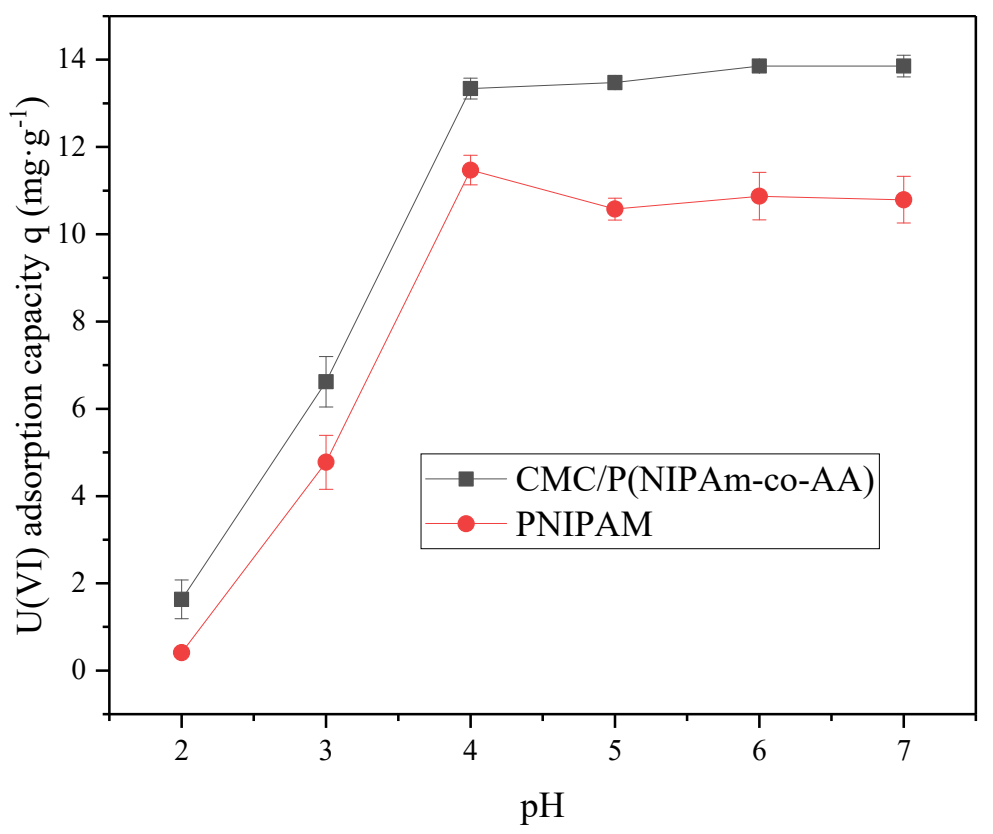

Figure 6. Effect of $\mathrm{pH}$ on $\mathrm{U}(\mathrm{VI})$ adsorption by CMC/P (NIPAM-co-AA) and PNIPAM.

\subsubsection{Adsorption Isotherm}

The effect of temperature $(293,303,308 \mathrm{~K})$ on U(VI) adsorption was studied under the condition of $\mathrm{pH}=4$. Ten milligrams of CMC/P (NIPAM-co-AA) was placed in the range of $2-100 \mathrm{mg} \cdot \mathrm{L}^{-1}$ initial concentrations of $\mathrm{U}(\mathrm{VI})$ solutions, over $1 \mathrm{~h}$. The adsorption isotherm was curve fitted by the Langmuir isothermal adsorption model of Equation (6) and the Freundlich isothermal adsorption model of Equation (7).

$$
\begin{aligned}
& \frac{C_{e}}{q_{e}}=\frac{1}{b \cdot q_{\max }}+\frac{C_{e}}{q_{\max }} \\
& \operatorname{In} q_{e}=\operatorname{In} k_{F}+\frac{1}{n} \operatorname{In} C_{e}
\end{aligned}
$$


where $C_{\mathrm{e}}\left(\mathrm{mg} \mathrm{L}^{-1}\right)$ is the $\mathrm{U}(\mathrm{VI})$ concentration of the adsorption equilibrium, $b$ is the constant of Langmuir adsorption equilibrium, $q_{\max }\left(\mathrm{mg} \mathrm{g}^{-1}\right)$ represents the amount of maximum adsorption, $\mathrm{k}_{\mathrm{F}}$ is the constant of Freundlich adsorption equilibrium, and $\mathrm{n}$ is the symbol of adsorption index.

The adsorption isotherm can be carried out to study the interaction of the adsorbent with the U(VI) to further determine the adsorption mechanism. Figure 7 shows the linear fittings curve of $\mathrm{CMC} / \mathrm{P}$ (NIPAM-co-AA) corresponding to the models of Langmuir and Freundlich. As the curve exhibits, the adsorption isotherm fits well to the Langmuir isothermal adsorption model. Table 7 is the isothermal adsorption model parameters calculated from fitting curves and equations. From those parameters, the adsorption model of the gel is dominated by the Langmuir model. At lower temperatures, uranium adsorption is more consistent with the Langmuir model, while adsorption is in line with two kinds of isotherm, which reveals that adsorption is more easily carried out on the surface of the hydrogel in a single layer; specifically adsorbed, with the temperature rising, the adsorption mode is uneven. Meanwhile, the adsorption amount is negatively correlated with the characteristic coefficient, $b$, for the degree of reaction adsorption, indicating that low temperature is favorable for adsorption. The maximum theoretical adsorption capacity is up to $285.71 \mathrm{mg} \mathrm{g}^{-1}$. This value is higher than the general hydrogel rather than the smart hydrogel that was determined for the graphene (rGO) hydrogel, with a maximum $\mathrm{U}(\mathrm{VI})$ adsorption capacity of $134.23 \mathrm{mg} \mathrm{g}^{-1}$ [38].

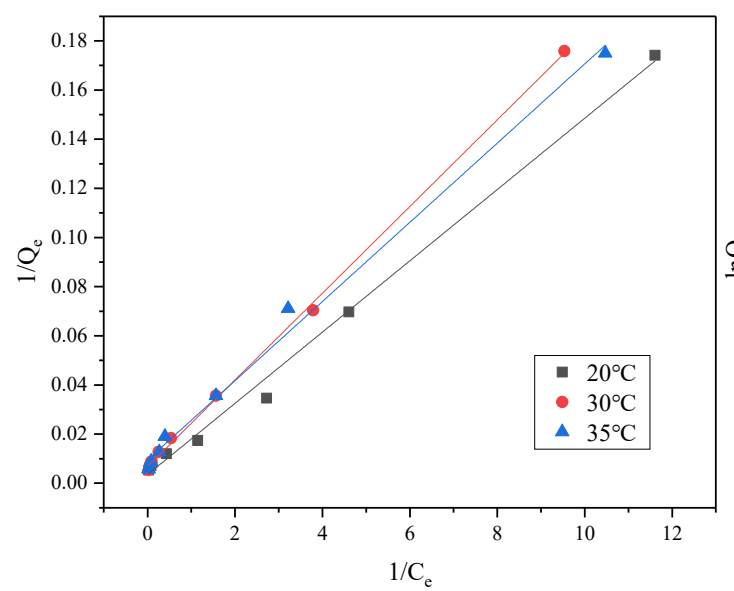

(a)

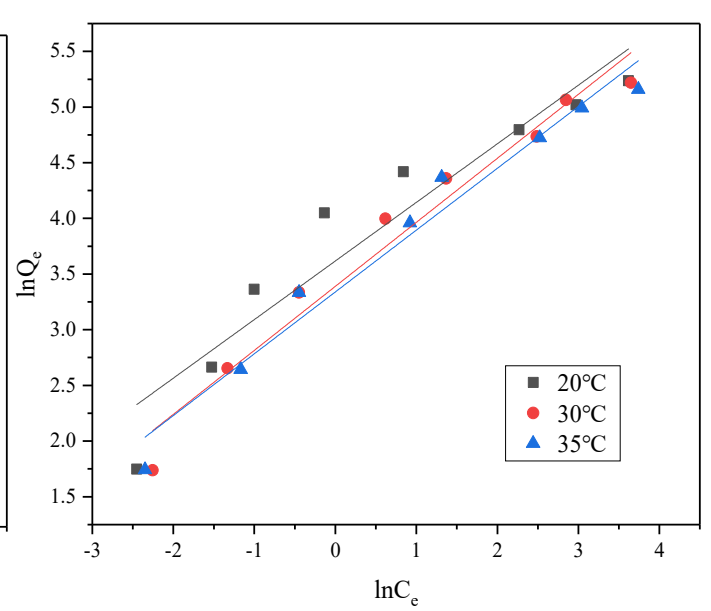

(b)

Figure 7. Fitting curve of Langmuir (a) and Freundlich (b) isothermal adsorption model of U(VI) adsorption by CMC/P-(NIPAM-co-AA).

Table 7. Langmuir and Freundlich isothermal adsorption model parameters of U(VI) adsorption by CMC/P (NIPAM-CO-AA).

\begin{tabular}{ccccccc}
\hline \multirow{2}{*}{$\mathbf{T} / \mathbf{K}$} & \multicolumn{3}{c}{ Langmuir } & \multicolumn{3}{c}{ Freundlich } \\
\cline { 2 - 7 } & $\boldsymbol{q}_{\text {max }} /\left(\mathbf{m g} \cdot \mathbf{g}^{-\mathbf{1}}\right)$ & $\boldsymbol{b}$ & $\boldsymbol{R}_{\mathbf{1}}{ }^{\mathbf{2}}$ & $\boldsymbol{k}_{\boldsymbol{F}}$ & $\boldsymbol{n}$ & $\boldsymbol{R}_{\mathbf{2}}{ }^{\mathbf{2}}$ \\
\hline 293 & 285.71 & 0.2414 & 0.9954 & 36.9439 & 1.8896 & 0.9128 \\
303 & 149.25 & 0.3807 & 0.9990 & 29.6571 & 1.7391 & 0.9673 \\
308 & 105.26 & 0.5901 & 0.9937 & 28.2022 & 1.8008 & 0.9690 \\
\hline
\end{tabular}

\subsection{Characterization Analysis of Hydrogel Before and After U(VI) Adsorption}

SEM images of the CMC/P (NIPAM-co-AA) hydrogel before $(\mathrm{a}, \mathrm{c})$ and after $(\mathrm{b}, \mathrm{d})$ adsorption of $\mathrm{U}(\mathrm{VI})$ with different magnification are illustrated in Figure 8. The images of Figure 8a,c show the obvious porous structure, but the porous structure of the hydrogel is non-uniform and has irregularities. This is due to uneven polymerization reaction. Moreover, the SEM images after the uptake of $\mathrm{UO}_{2}{ }^{2+}$ by the adsorbents show a reduced size in porous structure compared with those before the adsorption, which may imply that $\mathrm{UO}_{2}{ }^{2+}$ has been successfully bound to the adsorption site on the hydrogel. To prove the change in the pores before and after adsorption, a mercury injection test was performed. 
Figure 9 shows the Log differential pore size distribution curves of the CMC/P (NIPAM-co-AA) hydrogel before and after the uptake of U(VI). From Figure 9, pore size diameter is concentrated at $100,000 \mathrm{~nm}$ before and after $\mathrm{U}(\mathrm{VI})$-loading, and in Table 8 the average pore diameter before adsorption is much larger than that after adsorption. This result is consistent with previous SEM observations. The phenomenon may result from the fact that the adsorbed U(VI) blocked the channel structure of the hydrogel.

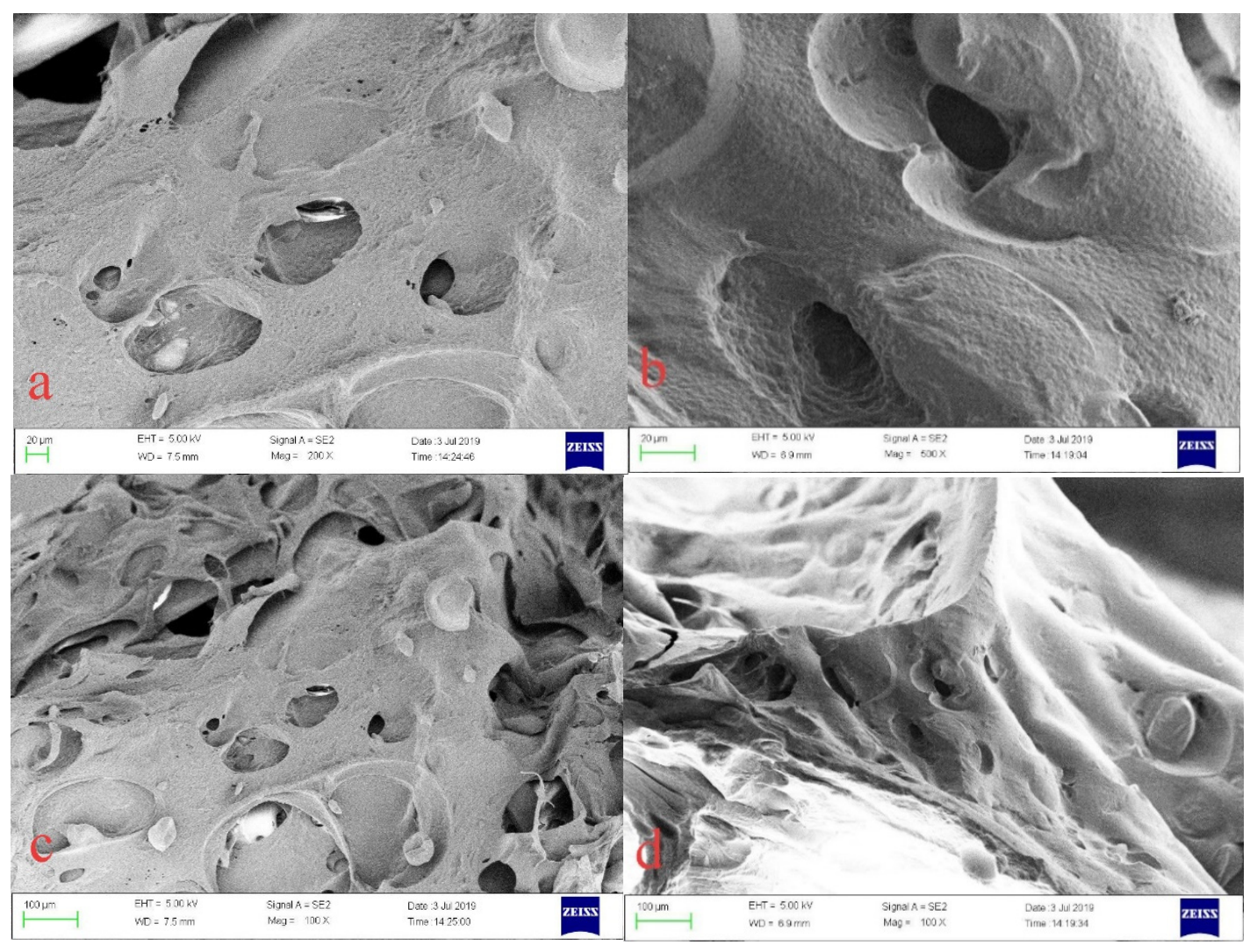

Figure 8. Scanning electron microscopy (SEM) micrographs of the CMC/P (NIPAM-co-AA) hydrogel before and after adsorption of U(VI): (a) before adsorption, $20 \mu \mathrm{m}$; (b) after adsorption, $20 \mu \mathrm{m}$; (c) before adsorption, $100 \mu \mathrm{m}$; and (d) after adsorption, $100 \mu \mathrm{m}$.

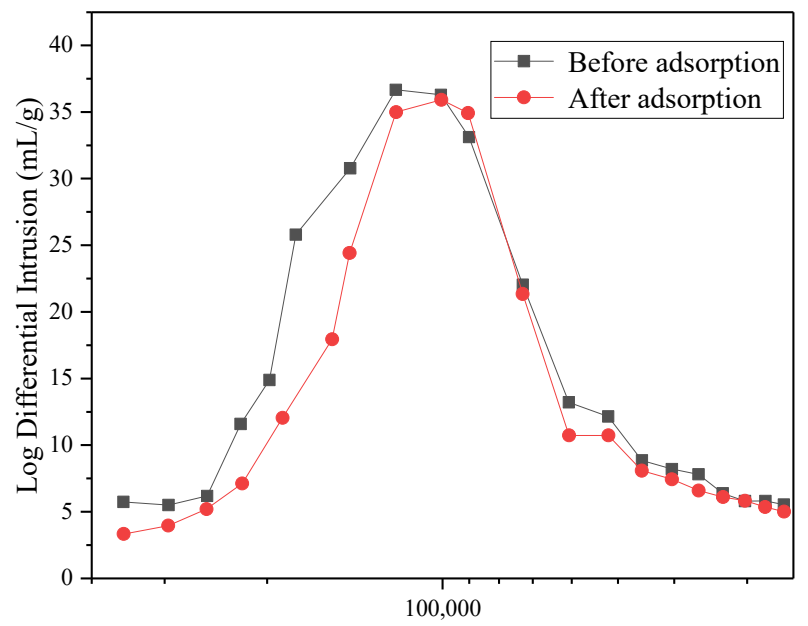

Pore size Diameter (nm)

Figure 9. Log differential pore size distribution curves of CMC/P (NIPAM-co-AA) hydrogel before and after $\mathrm{U}(\mathrm{VI})$-loading. 
Table 8. Mercury intrusion porosimetry (MIP) parameters of CMC/P (NIPAM-co-AA) hydrogel before and after U(VI)-loading.

\begin{tabular}{ccc}
\hline Sample & Average Pore Diameter (nm) & Porosity (\%) \\
\hline Before adsorption & $90,195.76$ & 97.89 \\
After adsorption & $21,469.33$ & 94.82 \\
\hline
\end{tabular}

The XPS spectra of the CMC/P (NIPAM-co-AA) hydrogel before and after the uptake of U(VI) were examined to contrast the possible elemental composition and adsorption mechanism. Comparing the XPS spectra in Figure 10, before and after adsorption, the two sharp and narrow peaks appeared at 391.08 and $379.74 \mathrm{eV}$, which belong to $\mathrm{U} 4 \mathrm{f}_{5 / 2}$ and $\mathrm{U} 4 \mathrm{f}_{7 / 2}$ [39], respectively. This phenomenon proved that no redox reaction occurred between the hydrogel and U(VI) [40], which further reveals that the uptake of $\mathrm{U}(\mathrm{VI})$ on the hydrogel was solely in the form of a positive hexavalent valence state [41]. Three peaks of O1s have been divided, attributing to $530.69 \mathrm{eV}$ for $\mathrm{C}=\mathrm{O}$ oxygen, $531.88 \mathrm{eV}$ for- $\mathrm{C}-\mathrm{OH}$ and $\mathrm{C}-\mathrm{O}$ oxygen, and $533.35 \mathrm{eV}$ for adsorbed $\mathrm{H}_{2} \mathrm{O}$ [42]. The O1s peaks of the carbonyl groups and the hydroxyl groups shifted to low binding energy, which could perhaps be ascribed to the interaction between $\mathrm{C}=\mathrm{O},-\mathrm{OH}$, and uranium via the covalent bond [43]. Bonding to $\mathrm{UO}_{2}{ }^{2+}$ would lead to a decrease of the electro-withdrawing ability of oxygen, so as to increase the electron density on the hydrogel, which in turn reduces its binding energy [44]. In consequence, the dominant mechanism for $\mathrm{UO}_{2}{ }^{2+}$ sorption on the hydrogel was due to the complexes formed between the oxygen-containing group and $\mathrm{U}(\mathrm{VI})$.
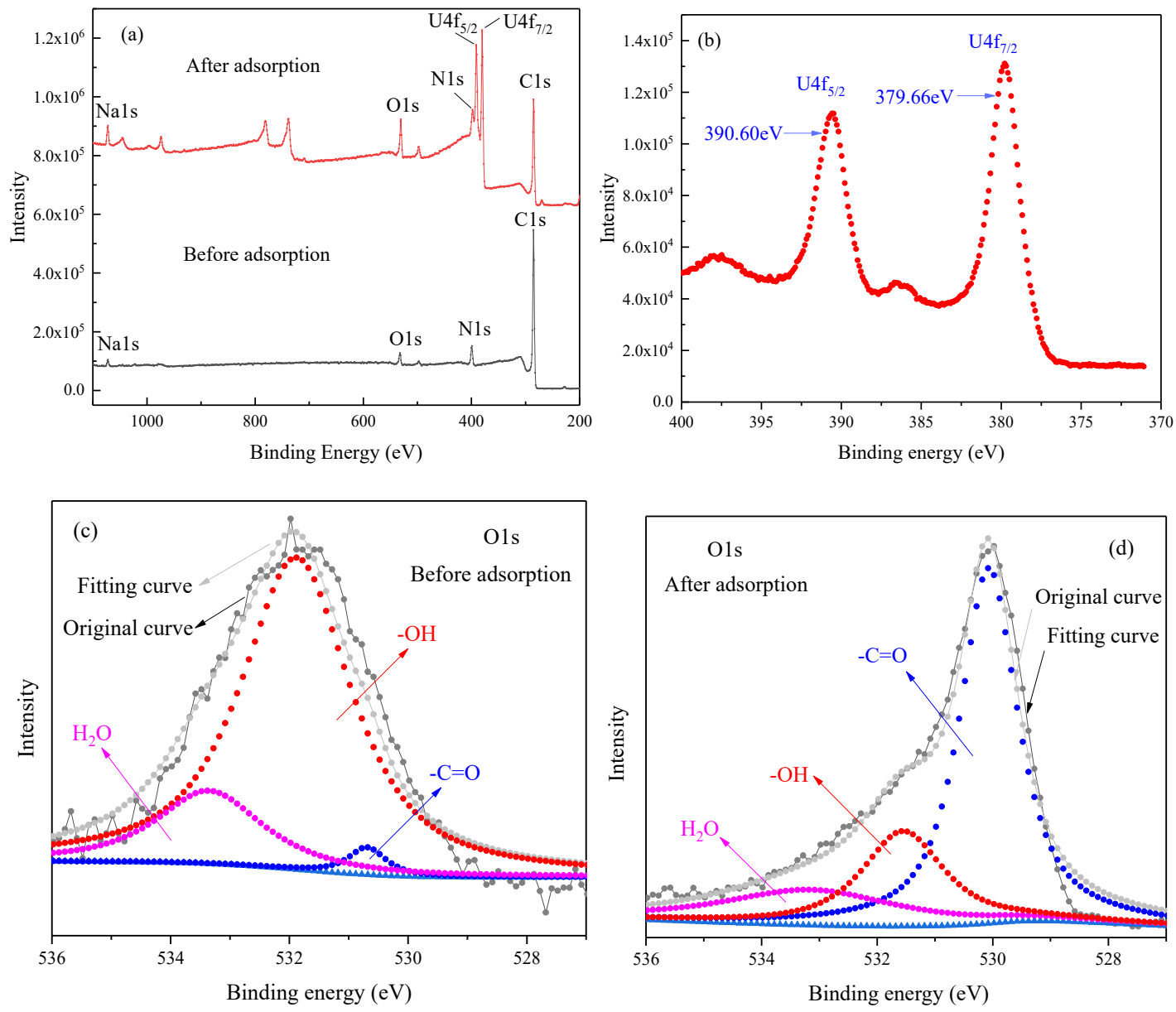

Figure 10. (a) XPS spectra of the CMC/P (NIPAM-co-AA) hydrogel before and after U(VI) adsorption, (b) high-resolution XPS spectra of U4f, and (c,d) O1s before and after adsorption. 


\subsection{Chemical Modification of Hydrogel}

To confirm the successful chemical modification of the hydrogel, the FTIR of CMC/P (NIPAM-co-AA) before and after the functional groups shielded are presented in Figure 11. The curve of comparison is the untreated hydrogel. The peak of $1634 \mathrm{~cm}^{-1}$ was changed to $1645 \mathrm{~cm}^{-1}$ after the carboxyl groups were shielded, which was attributed to the interaction by the bending vibration of $\mathrm{C}=\mathrm{O}$ and the stretching vibration of $\mathrm{N}-\mathrm{H}$. For comparison, the peak of $3449 \mathrm{~cm}^{-1}$ of the hydrogen bond disappeared after the carboxyl groups and the acylamino groups were shielded. After the hydroxyl groups were shielded, the peak of $3449 \mathrm{~cm}^{-1}$ of the hydrogen bond turned into $3304 \mathrm{~cm}^{-1}$. It has been speculated before that the cross-linking network was formed between the chain of CMC and the polymerase chain of P (NIPAM-co-AA), which caused some peaks to be covered. Interestingly, after chemical modification of the hydrogel, some peaks appeared. This may be attributed to the fact that the chemical modification of hydrogel exposes some parts of the hydrogel.

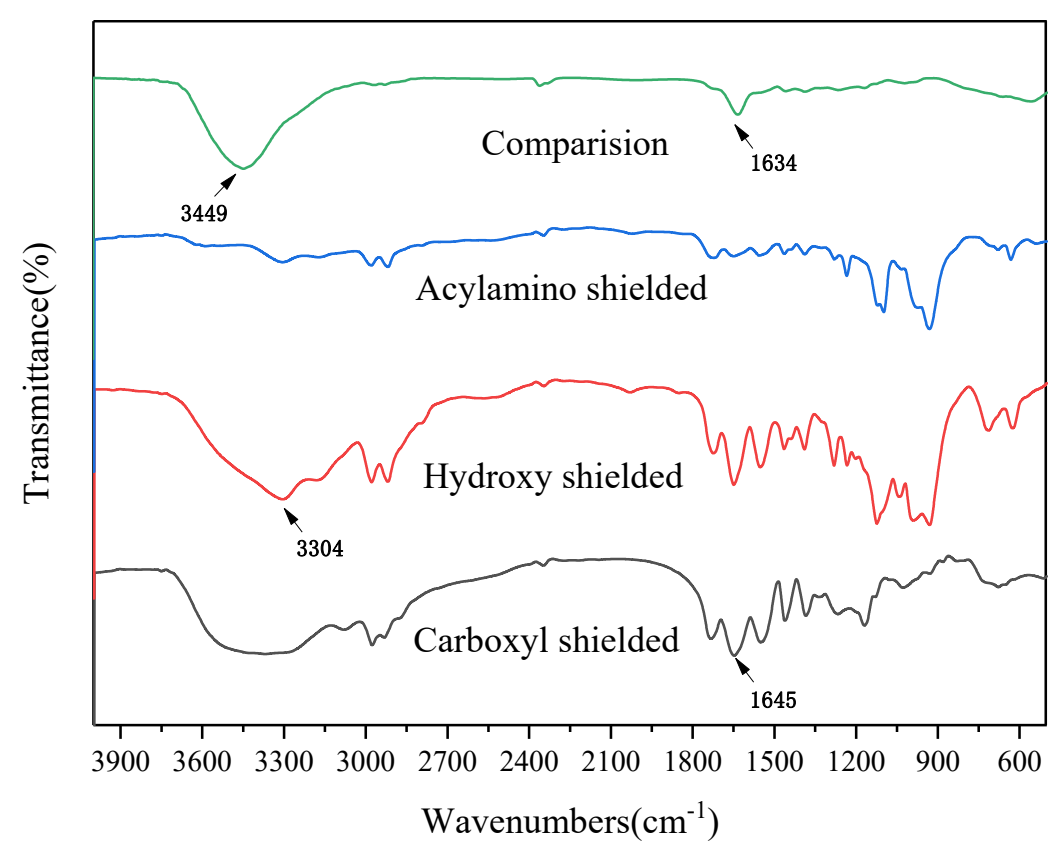

Figure 11. FTIR of CMC/P (NIPAM-co-AA) before and after the functional groups were shielded.

After the chemical modification of the carboxyl groups, the hydroxyl groups, and the acylamino groups, the gel was added to a $30 \mathrm{~mL}$ uranium solution under the optimum adsorption condition of $\mathrm{pH}=4$ and temperature of $20^{\circ} \mathrm{C}$ to analyze the effect of each reactive group on adsorption. From the results in Figure 12, for comparison, the $\mathrm{U}(\mathrm{VI})$ adsorption was reduced by $15.58 \%, 13.01 \%$, and $9.46 \%$ after the carboxyl groups, the hydroxyl groups, and the acylamino groups, respectively, were shielded, which indicated that the carboxyl groups, the hydroxyl groups, and the acylamino groups could provide sorption sites for $\mathrm{U}(\mathrm{VI})$. Besides, the capability of the gel to adsorb $\mathrm{U}(\mathrm{VI})$ was legibly decreased when the $-\mathrm{COOH}$ esterifies, while the hydrogel could hardly immobilize $\mathrm{U}(\mathrm{VI})$ after -CONH was being shielded. Therefore, the inference was that the acylamino group has a greater impact on the adsorption of $\mathrm{U}(\mathrm{VI})$ than the carboxyl groups and the hydroxyl groups, which may be associated with the coordination mode of the functional groups with uranium [45] or more acylamino groups on the surface of the gel [27]. This verdict may provide a reference for the uranium adsorption mechanism. In Figure 13, two oxygen atoms belonging to the carboxyl groups or the hydroxyl groups can bind to uranium atoms. The nitrogen atoms of the acylamino groups can coordinate with $\mathrm{UO}_{2}{ }^{2+}[46,47]$. 


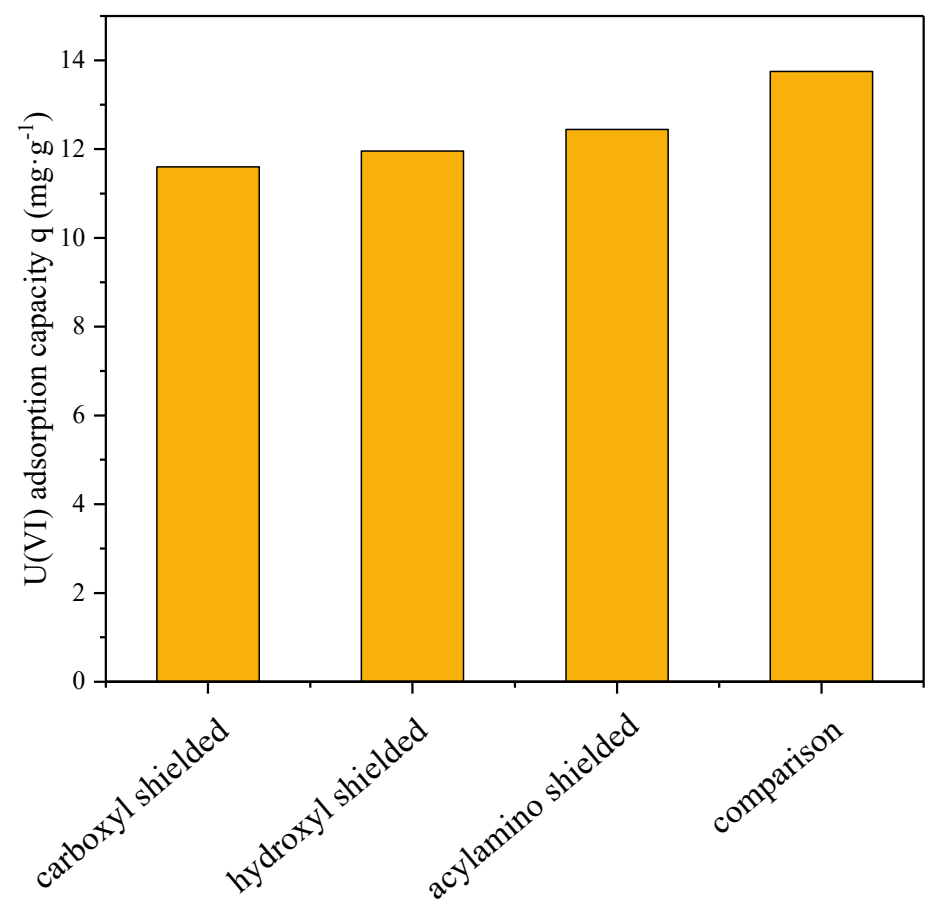

Figure 12. U(VI) adsorption capacity after the functional groups were shielded.

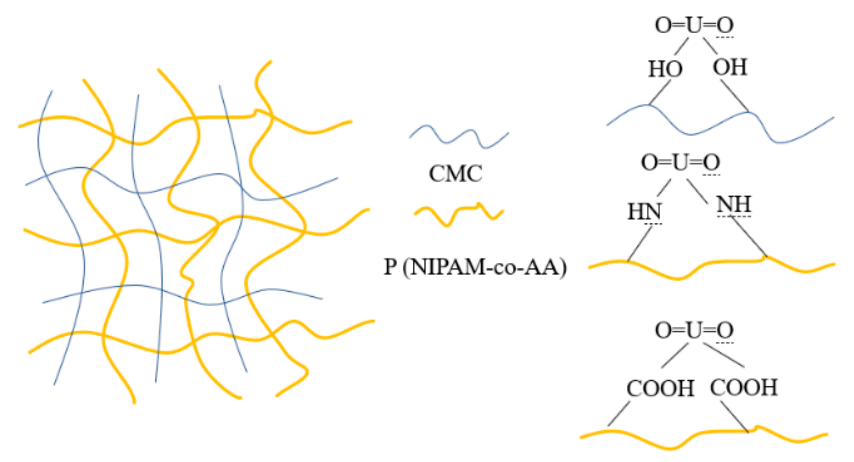

Figure 13. The proposed mechanism of the CMC/P (NIPAM co-AA) hydrogel interaction with $\mathrm{UO}_{2}{ }^{2+}$.

\subsection{Desorption and Reusability Analysis}

To examine the desorption property of the composite hydrogel after adsorption, the gel was adsorbed to equilibrium under optimal adsorption conditions. The sorbed hydrogel was then washed with deionized water and was immersed in $0.01 \mathrm{~mol} \mathrm{~L}^{-1}$ and in $0.1 \mathrm{~mol} \mathrm{~L}^{-1}$ of $\mathrm{HNO}_{3}$ solutions separately for different times, the resolution of the $\mathrm{U}(\mathrm{VI})$ was calculated, and the result was shown that the hydrogels have a good desorption effect in $0.1 \mathrm{~mol} \mathrm{~L}^{-1} \mathrm{HNO}_{3}$ solution, so the $0.1 \mathrm{~mol} \mathrm{~L}^{-1} \mathrm{HNO}_{3}$ solution was chosen as the desorption reagent.

As shown in Figure 14, within 5 to $60 \mathrm{~min}$, the rate of desorption of the composite hydrogel increased with time at different temperatures, and the resolution rate increased significantly with the rise in temperature, which verified that the thermo-sensitive hydrogel was "adsorbed at low temperature and desorbed at high temperature". After desorption for $2 \mathrm{~h}$, the desorption rate decreased at different temperatures, indicating that the hydrogel had different degrees of re-absorption. Among them, the curve decreased most at $20^{\circ} \mathrm{C}$ while, at $50{ }^{\circ} \mathrm{C}$, the decline was the slowest, which therefore indicated that the composite hydrogel was suitable for adsorption at low temperatures, and the desorption was faster with a smaller re-absorption amount at high temperatures. 


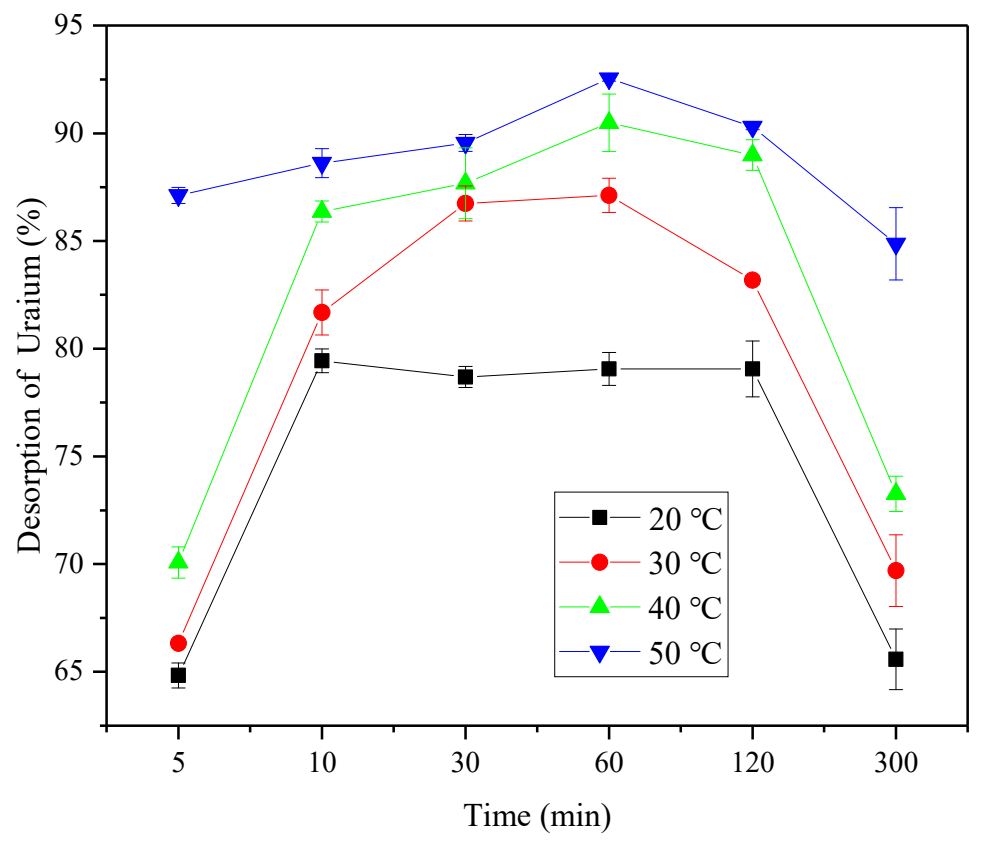

Figure 14. Desorption of Uranium at different temperatures.

To examine the reusability of the CMC/P (NIPAM-co-AA) hydrogel, it was subjected to alternate heating at $20^{\circ} \mathrm{C}$ and then at $50{ }^{\circ} \mathrm{C}$ in five cycles to determine the adsorption-desorption of U(VI) in solution. The five cycles of temperature swing adsorption-desorption are shown in Figure 15. The experiment showed that the resolution rate was still available at approximately $77.74 \%$ after five cycles of temperature swing adsorption-desorption. The results have shown that the composite hydrogel has a high desorption efficiency and the sorbed U(VI) can be easily recovered to allow a high recyclability of the hydrogel. Therefore, the hydrogel is suitable for treatment of wastewater containing low concentrations of uranium. However, the specific reason for the amount of loss of the sorbed U(VI) at 20 and $50{ }^{\circ} \mathrm{C}$ during the heating cycle is unclear. However, this phenomenon is consistent with Tokuyama's research [48].

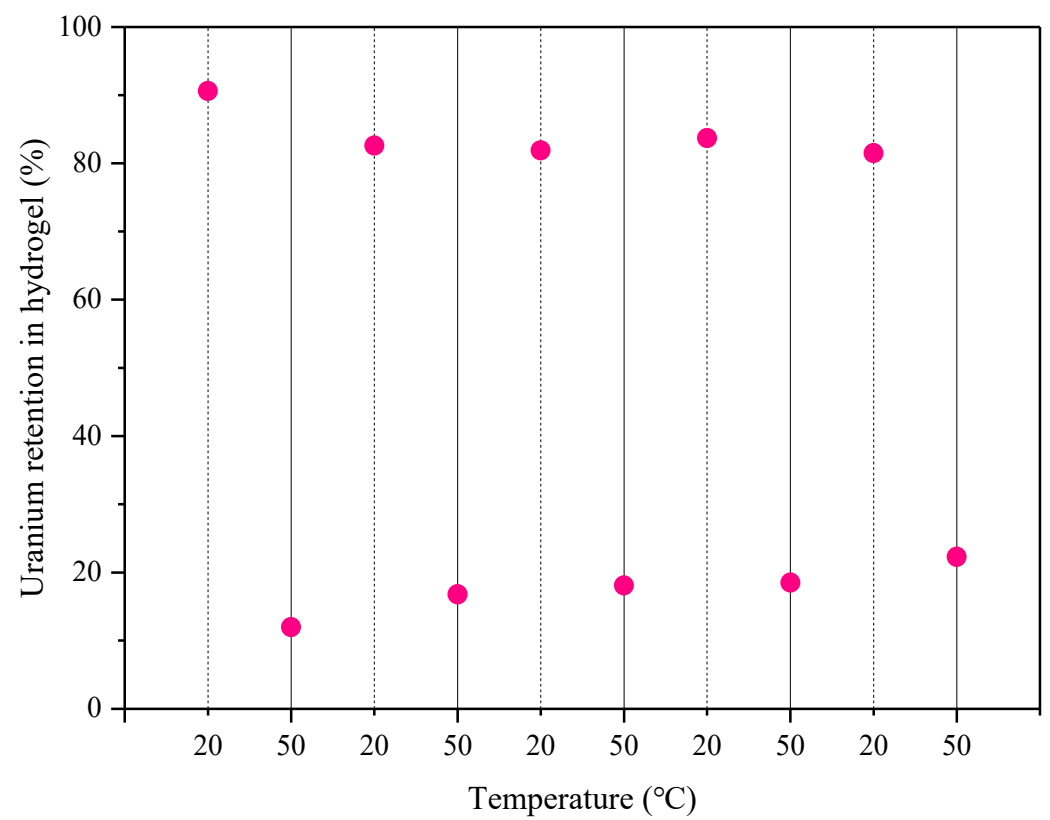

Figure 15. The uranium retention in hydrogel of temperature swing adsorption-desorption. 


\section{Conclusions}

The optimized preparation method of the thermo-sensitive hydrogel of CMC/P (NIPAM-co-AA) was evaluated by L16 $\left(4^{5}\right)$ orthogonal experiments. The effect of polymerization temperature on the properties of gels was the most significant of the synthesis factors. The hydrogel was used to determine the $\mathrm{U}(\mathrm{VI})$ adsorption for wastewater treatment. The adsorption reached equilibrium within $1 \mathrm{~h}$. Under the reaction of $\mathrm{pH}=6$ and a temperature of $298 \mathrm{~K}$, the initial concentration of $\mathrm{U}(\mathrm{VI}) 5 \mathrm{mg} \cdot \mathrm{L}^{-1}$, and $10 \mathrm{mg}$ of CMC/P (NIPAM-co-AA) hydrogel, the maximum adsorption capacity was $14.69 \mathrm{mg} \cdot \mathrm{g}^{-1}$. The kinetics fitted perfectly with the pseudo-second-order model, and the isotherms for composite hydrogel adsorption of $\mathrm{U}(\mathrm{VI})$ was in accordance with the Langmuir model. In the desorption and reusability study, low temperature has a beneficial effect for the adsorption of $\mathrm{U}(\mathrm{VI})$, while high temperature is good for desorption. The resolution rate was about $77.74 \%$ after five cycles of alternate temperature heating at 20 and $50{ }^{\circ} \mathrm{C}$ to determine the adsorption-desorption of the hydrogel. The chemical modification of the hydrogel showed that the carboxyl group has the highest adsorption capacity for uranium adsorption. The XPS spectra confirmed that the dominant mechanisms were the complexes between the oxygen-containing group and $\mathrm{U}(\mathrm{VI})$ for $\mathrm{UO}_{2}{ }^{2+}$ sorption by the hydrogel. Therefore, the temperature-sensitive CMC/P (NIPAM-co-AA) hydrogel is a potential intelligent adsorption material for the removal of $\mathrm{U}(\mathrm{VI})$ in low-concentration uranium-containing wastewater.

Author Contributions: Writing, J.T.; validation, G.W.; supervision, P.C.; project administration, S.X.; review and editing, T.Z., C.W.Y., and H.H. All authors have read and agreed to the published version of the manuscript.

Funding: This research was funded by the National Natural Scientific Foundation of China (NO.11475080) and the Postgraduate Research Innovation Project at the University of South China (NO.193YXC017).

Acknowledgments: The authors are grateful to the Laboratory of Pollution Control and Resource Technology and the Department of Municipal Engineering at the University of South China for providing the necessary facilities for the research.

Conflicts of Interest: The authors declare no conflict of interest.

\section{References}

1. Stassen, L.; Suthiram, J. Initial development of an alkaline process for recovery of uranium from Mo-99 production process waste residue. J. Radioanal. Nucl. Chem. 2015, 305, 41-50. [CrossRef]

2. Zhao, G.X.; Huang, X.B.; Tang, Z.W.; Huang, Q.F.; Niu, F.L.; Wang, X.K. Polymer-based nanocomposites for heavy metal ions removal from aqueous solution: A review. Polym. Chem. 2018, 9, 3562-3582. [CrossRef]

3. Hui, L.; Zhai, F.W.; Gui, D.X.; Wang, X.X.; Wu, C.F.; Duo, Z.; Xing, D.; Hong, D.; Su, X.T.; Juan, D.; et al. Powerful uranium extraction strategy with combined ligand complexation and photocatalytic reduction by postsynthetically modified photoactive metal-organic frameworks. Appl. Catal. B-Environ. 2019, 254, 47-54.

4. Chen, T.; Zhang, J.; Li, M.X.; Ge, H.L.; Li, Y.; Duan, T.; Zhu, W.K. Biomass-derived composite aerogels with novel structure for removal/recovery of uranium from simulated radioactive wastewater. Nanotechnology 2019, 30, 45. [CrossRef]

5. Irani, M.; Ismail, H.; Ahmad, Z. Preparation and properties of linear low-density polyethylene-g-poly (acrylic acid)/organo-montmorillonite superabsorbent hydrogel composites. Polym. Test. 2013, 32, 502-512. [CrossRef]

6. Wu, Y.H.; Pang, H.W.; Liu, Y.; Wang, X.X.; Yu, S.J.; Fu, D.; Chen, J.R.; Wang, X.K. Environmental remediation of heavy metal ions by novel-nanomaterials: A review. Environ. Pollut. 2019, 246, 608-620. [CrossRef]

7. Depa, K.; Strachota, A.; Slouf, M.; Brus, J. Poly(N-isopropylacrylamide)-SiO ${ }_{2}$ nanocomposites interpenetrated by starch: Stimuli-responsive hydrogels with attractive tensile properties. Eur. Polym. J. 2017, 88, 349-372. [CrossRef]

8. Wei, Y.B.; Zeng, Q.; Wang, M.; Huang, J.Z.; Guo, X.R.; Wang, L.S. Near-infrared light-responsive electrochemical protein imprinting biosensor based on a shape memory conducting hydrogel. Biosens. Bioelectron. 2019, 131, 156-162. [CrossRef] 
9. Dai, H.J.; Zhang, H.; Ma, L.; Zhou, H.Y.; Yu, Y.; Guo, T.; Zhang, Y.H.; Huang, H.H. Green pH/magnetic sensitive hydrogels based on pineapple peel cellulose and polyvinyl alcohol: Synthesis, characterization and naringin prolonged release. Carbohydr. Polym. 2019, 209, 51-61. [CrossRef]

10. Liu, Z.J.; Xu, G.R.; Wang, C.N.; Li, C.Y.; Yao, P. Shear-responsive injectable supramolecular hydrogel releasing doxorubicin loaded micelles with $\mathrm{pH}$-sensitivity for local tumor chemotherapy. Int. J. Pharm. 2017, 530, 53-62. [CrossRef]

11. Suzuki, A.; Tanaka, T.J.N. Phase transition in polymer gels induced by visible light. Nature 1990, 346, $345-347$. [CrossRef]

12. Qin, H.L.; Zhang, T.; Li, N.; Cong, H.P.; Yu, S.H. Anisotropic and self-healing hydrogels with multi-responsive actuating capability. Nat. Commun. 2019, 10, 2202. [CrossRef] [PubMed]

13. Wang, M.; Payne, K.A.; Tong, S.; Ergas, S.J. Hybrid algal photosynthesis and ion exchange (HAPIX) process for high ammonium strength wastewater treatment. Water Res. 2018, 142, 65-74. [CrossRef] [PubMed]

14. Xia, M.; Pan, S.X.; Sun, Y.J.; Luo, Q.Z.; Fang, Z.P.; He, P.X.; Fu, J.; Zhang, Y.H. Dehydration behaviours of isopropyl group initiate the surface wettability transition of temperature sensitive poly(N-isopropylacrylamide) hydrogel. Mater. Res. Express 2019, 6, 095704. [CrossRef]

15. Iatridi, Z.; Saravanou, S.F.; Tsitsilianis, C. Injectable self-assembling hydrogel from alginate grafted by $\mathrm{P}(\mathrm{N}$-isopropylacrylamide-co-N-tert-butylacrylamide) random copolymers. Carbohydr. Polym. 2019, 219, 344-352. [CrossRef] [PubMed]

16. Benhalima, T.; Ferfera-Harrar, H.; Lerari, D. Optimization of carboxymethyl cellulose hydrogels beads generated by an anionic surfactant micelle templating for cationic dye uptake: Swelling, sorption and reusability studies. Int. J. Biol. Macromol. 2017, 23, 2558-2564. [CrossRef]

17. Ju, X.J.; Zhang, S.B.; Zhou, M.Y.; Xie, R.; Yang, L.; Chu, L.Y. Novel heavy-metal adsorption material: Ion-recognition P(NIPAM-co-BCAm) hydrogels for removal of lead(II) ions. J. Hazard. Mater. 2009, 167, 114-118. [CrossRef] [PubMed]

18. Yan, F.; Meng, W.; Cao, D.; Guo, S.; Li, C. Preparation of thermosensitive, calix[4]arene incorporated P(NIPAM-co-HBCalix) hydrogel as a reusable adsorbent of nickel(II) ions. J. Polym. Sci. Part A Polym. Chem. 2013, 51, 2401-2408. [CrossRef]

19. Dewangan, T.; Tiwari, A.; Bajpai, A.K. Removal of Chromium(VI) Ions by Adsorption onto Binary Biopolymeric Beads of Sodium Alginate and Carboxymethyl Cellulose. J. Dispers. Sci. Technol. 2011, 32, 1075-1082. [CrossRef]

20. Jin, H.X.; Xu, H.P.; Wang, N.; Yang, L.Y.; Wang, Y.G.; Yu, D.; Ouyang, X.K. Fabrication of Carboxymethylcellulose/Metal-Organic Framework Beads for Removal of $\mathrm{Pb}$ (II) from Aqueous Solution. Materials 2019, 12, 942. [CrossRef] [PubMed]

21. Godiya, C.B.; Cheng, X.; Li, D.W.; Chen, Z.; Lu, X.L. Carboxymethyl cellulose/polyacrylamide composite hydrogel for cascaded treatment/reuse of heavy metal ions in wastewater. J. Hazard. Mater. 2019, 364, $28-38$. [CrossRef] [PubMed]

22. Chen, Y.S.; Long, Y.W.; Li, Q.; Chen, X.H.; Xu, X. Synthesis of high-performance sodium carboxymethyl cellulose-based adsorbent for effective removal of methylene blue and $\mathrm{Pb}$ (II). Int. J. Biol. Macromol. 2019, 126, 107-117. [CrossRef] [PubMed]

23. Sun, Y.; Liu, Y.L.; Lou, Z.M.; Yang, K.L.; Lv, D.; Zhou, J.S.; Baig, S.A.; Xu, X.H. Enhanced performance for $\mathrm{Hg}$ (II) removal using biomaterial (CMC/gelatin/starch) stabilized FeS nanoparticles: Stabilization effects and removal mechanism. Chem. Eng. J. 2018, 344, 616-624. [CrossRef]

24. Gökçeören, A.T.; Şenkal, B.F.; Erbil, C. Effect of crosslinker structure and crosslinker/monomer ratio on network parameters and thermodynamic properties of Poly (N-isopropylacrylamide) hydrogels. J. Polym. Res. 2014, 21, 370. [CrossRef]

25. Ozkahraman, B.; Acar, I.; Emik, S. Removal of $\mathrm{Cu}^{2+}$ and $\mathrm{Pb}^{2+}$ Ions Using $\mathrm{CMC}$ Based Thermoresponsive Nanocomposite Hydrogel. Clean-Soil Air Water 2011, 39, 658-664. [CrossRef]

26. Qi, X.H.; Liu, M.Z.; Chen, Z.B.; Zhang, F. Study on the swelling kinetics of superabsorbent using open circuit potential measurement. Eur. Polym. J. 2008, 44, 743-754. [CrossRef]

27. Zhang, J.; Song, H.; Chen, Z.; Liu, S.S.; Wei, Y.L.; Huang, J.Y.; Guo, C.L.; Dang, Z.; Lin, Z. Biomineralization mechanism of $\mathrm{U}(\mathrm{VI})$ induced by Bacillus cereus 12-2: The role of functional groups and enzymes. Chemosphere 2018, 206, 682-692. [CrossRef] 
28. Kapoor, A.; Viraraghavan, T. Heavy metal biosorption sites in Aspergillus niger. Bioresour. Technol. 1997, 61, 221-227. [CrossRef]

29. Zhang, M.; Li, Y.; Yang, Q.; Huang, L.; Chen, L.; Ni, Y.; Xiao, H.J.C.P. Temperature and pH Responsive Cellulose Filament/Poly (NIPAM-co-AAc) Hybrids as Novel Adsorbent towards $\mathrm{Pb}$ (II) Removal. Carbohydr. Polym. 2018, 195, 495. [CrossRef]

30. Chang, C.Y.; Han, K.; Zhang, L.N. Structure and properties of cellulose/poly(N-isopropylacrylamide) hydrogels prepared by IPN strategy. Polym. Adv. Technol. 2011, 22, 1329-1334. [CrossRef]

31. Wu, J.; Zhou, Y.M.; Meng, Y.; Zhang, J.X.; Liu, Q.B.; Cao, Q.M.; Yu, Y.Q. Synthesis and properties of sodium alginate/poly(acrylic acid) double-network superabsorbent. E-Polym. 2015, 15, 271-278. [CrossRef]

32. Wan, X.F.; Guo, C.B.; Li, Y.M.; Chai, X.S.; Lin, K.; Chen, G.X.; Ali, A. A Zero-Valent Pd/Fe Loaded and Nanofibrillated Cellulose-Reinforced Carboxymethyl Cellulose Hydrogel for Dechlorination of 2,4,6-Trichlorophenol. J. Nanosci. Nanotechnol. 2019, 19, 7261-7268. [CrossRef] [PubMed]

33. Meenakshi, S.; Devi, S.; Pandian, K.; Chitra, K.; Tharmaraj, P. Aniline-mediated synthesis of carboxymethyl cellulose protected silver nanoparticlesmodified electrode for the differential pulse anodic stripping voltammetry detection of mercury at trace level. Ionics 2019, 25, 3431-3441. [CrossRef]

34. Wang, X.; Hou, H.; Li, Y.; Wang, Y.; Hao, C.; Ge, C. A novel semi-IPN hydrogel: Preparation, swelling properties and adsorption studies of Co (II). J. Ind. Eng. Chem. 2016, 41, 82-90. [CrossRef]

35. Bakhshali, M.; Zahra, M.; Mehdi, J. A starch-based stimuli-responsive magnetite nanohydrogel as de novo drug delivery system. Int. J. Biol. Macromol. 2018, 117, 418-426.

36. Cheng, J.; Shan, G.; Pan, P.J.R.A. Temperature and pH-dependent swelling and copper(II) adsorption of poly(N-isopropylacrylamide) copolymer hydrogel. RSC Adv. 2015, 5, 62091-62100. [CrossRef]

37. Liu, Y.; Liu, Y.; Cao, X.; Hua, R.; Wang, Y.; Pang, C.; Hua, M.; Li, X. Biosorption studies of uranium (VI) on cross-linked chitosan: Isotherm, kinetic and thermodynamic aspects. J. Radioanal. Nucl. Chem. 2011, 290, 231-239. [CrossRef]

38. He, Y.R.; Li, S.C.; Li, X.L.; Yang, Y.; Tang, A.M.; Du, L.; Tan, Z.Y.; Zhang, D.; Chen, H.B. Graphene (rGO) hydrogel: A promising material for facile removal of uranium from aqueous solution. Chem. Eng. J. 2018, 338, 333-340. [CrossRef]

39. Song, S.; Wang, K.; Zhang, Y.H.; Wang, Y.K.; Zhang, C.L.; Wang, X.; Zhang, R.; Chen, J.R.; Wen, T.; Wang, X.K. Self-assembly of graphene oxide/PEDOT:PSS nanocomposite as a novel adsorbent for uranium immobilization from wastewater. Environ. Pollut. 2019, 250, 196-205. [CrossRef]

40. Tu, J.W.; Peng, X.Q.; Wang, S.T.; Tian, C.; Deng, H.; Dang, Z.; Lu, G.N.; Shi, Z.Q.; Lin, Z. Effective capture of aqueous uranium from saline lake with magnesium-based binary and ternary layered double hydroxides. Sci. Total Environ. 2019, 677, 556-563. [CrossRef]

41. Liang, L.L.; Lin, X.Y.; Sun, S.Y.; Chen, Y.; Shang, R.; Luo, X.G. Stereoscopic porous gellan gum-based microspheres as high performance adsorbents for U(VI) removal. J. Radioanal. Nucl. Chem. 2019, 319, 213-225. [CrossRef]

42. Ding, C.C.; Cheng, W.C.; Nie, X.Q.; Niu, Z.W.; Duan, T.; Zhang, Y.Y.; Asiri, A.M.; Marwani, H.M.; Li, Y.; Sun, Y.B. Spectroscopic and theoretical investigation on efficient removal of U(VI) by amine-containing polymers. Chem. Eng. J. 2019, 367, 94-101. [CrossRef]

43. Yang, S.; Ji, G.X.; Cai, S.Y.; Xu, M.Y.; Hua, D.B. Polypropylene nonwoven fabric modified with oxime and guanidine for antibiofouling and highly selective uranium recovery from seawater. J. Radioanal. Nucl. Chem. 2019, 321, 323-332. [CrossRef]

44. Wu, L.; Lin, X.; Zhou, X.; Luo, X. Removal of uranium and fluorine from wastewater by double-functional microsphere adsorbent of SA/CMC loaded with calcium and aluminum. Appl. Surf. Sci. 2016, 384, 466-479. [CrossRef]

45. Wei, Y.L.; Chen, Z.; Song, H.; Zhang, J.; Lin, Z.; Dang, Z.; Deng, H. The immobilization mechanism of U(VI) induced by Bacillus thuringiensis 016 and the effects of coexisting ions. Biochem. Eng. J. 2019, 144, 57-63. [CrossRef]

46. Gao, J.K.; Hou, L.-A.; Zhang, G.-H.; Gu, P.J. Facile functionalized of SBA-15 via a biomimetic coating and its application in efficient removal of uranium ions from aqueous solution. J. Hazard. Mater. 2015, 286, 325-333. [CrossRef] 
47. Abney, C.W.; Mayes, R.T.; Saito, T.; Dai, S.J. Materials for the Recovery of Uranium from Seawater. Chem. Rev. 2017, 23, 13935-14013. [CrossRef]

48. Tokuyama, H.; Onodera, M.; Ban, T. Selective temperature-swing adsorption of Pd(II) ions onto a poly(N-isopropylacrylamide-co-allyl mercaptan) gel. Sep. Purif. Technol. 2017, 182, 166-170. [CrossRef] 